\title{
Study on the Correlation between Community Construction Planning Factors and the Spatial Distribution of COVID-19 Outbreak: Case Study of Main Urban Area of Wuhan
}

\author{
Caijuan Liang1, Jun Wang1, Zhihao Ma1, Shouni Tang1 ${ }^{*}$, Bo Wang1, Yue Wu ${ }^{2}$ \\ ${ }^{1}$ School of Civil Engineering and Architecture, Wuhan University of Technology, Wuhan, China \\ ${ }^{2}$ School of Architecture and Urban Planning, Huazhong University of Science and Technology, Wuhan, China \\ Email: *233683339@qq.com
}

How to cite this paper: Liang, C. J., Wang, J., Ma, Z. H., Tang, S. N., Wang, B., \& Wu, Y. (2021). Study on the Correlation between Community Construction Planning Factors and the Spatial Distribution of COVID-19 Outbreak: Case Study of Main Urban Area of Wuhan. Current Urban Studies, 9, 502531.

https://doi.org/10.4236/cus.2021.93031

Received: August 12, 2021

Accepted: September 4, 2021

Published: September 7, 2021

Copyright (อ 2021 by author(s) and Scientific Research Publishing Inc. This work is licensed under the Creative Commons Attribution International License (CC BY 4.0).

http://creativecommons.org/licenses/by/4.0/ (c) (i) Open Access

\begin{abstract}
In the context of the global outbreak of COVID-19, this study took Wuhan as an example, using mathematical statistics and spatial analysis, and other methods to explore the distribution characteristics and distribution of COVID19 in residential spaces in the main city of Wuhan. Based on the above analysis, this study summarized the influencing factors and revealed their internal connection with the spread of the epidemic, and finally proposed corresponding prevention and control strategies. The results show that: 1) The epidemic in Wuhan has significant spatial aggregation characteristics, with epidemic communities concentrated in urban areas with high population density and dense commercial areas along the Changjiang River more likely to be infected; 2) The construction planning factors of epidemic communities are closely related to epidemic density. The results indicated traffic convenience, business services and the accessibility of hospitals are significantly related to the spread of the virus. The epidemic density is highly negatively correlated with community's land area, base area, number of households, building height, building spacing, and completion time, and may negatively correlated with the number of buildings, greening rate. But it positively correlated with community's building density. Therefore, the epidemic prevention and control of urban residential spaces should start with improving the built environment of the community. It means, by creating a rich and diverse community flexible space, the community can effectively prevent the epidemic, and then realize the city's comprehensive anti-epidemic and development growth.
\end{abstract}




\section{Keywords}

Construction Planning Factors, COVID-19 Outbreak, Spatial Clustering, Community, Wuhan City

\section{Introduction}

According to statistics from the real-time big data of the epidemic and the National Health Commission, the cumulative number of COVID-19 cases in the world has reached 190 million, and the cumulative number of confirmed cases in China has reached 92,875, with 199 con-firmed cases and 2 suspected cases until July 30, 2021. Thanks to the concerted efforts of the Chinese people, the epidemic has been basically under control in China. But in the past two years, the rebound of the epidemic in some regions has continued globally.

COVID-19 is an infectious disease caused by a newly discovered coronavirus (SARS-CoV-2). Epidemiological analysis showed that the SARS-CoV-2 virus is mainly transmitted through droplets of saliva, or expelled from the nose when the infected person coughs or sneezes. The incubation period is $1-14$ days, and most people infected with the SARS-CoV-2 virus will experience mild to moderate respiratory disease. Elder infected people, as well as those with underlying medical problems, are more likely to experience severe symptoms such as difficulty breathing or loss of speech and motor function.

COVID-19 is known as a sudden acute infectious disease in epidemiology. Since the outbreak of the epidemic, COVID-19 has posed a serious threat to the life safety of urban residents and the social stability of the city (Jin, 2003). The COVID-19, like the spread of AIDS and SARS, closely related to the structure, morphology and function of urban space. The Lancet also reported that cities are perhaps the greatest threat to human health, and the breeding grounds and hotbeds of the deadliest known virus after SARS. With the improvement of modern urbanization, urban material and spatial environmental problems such as urban population expansion, traffic congestion and environmental pollution have accelerated or even multiplied the spread of the epidemic (Yang et al., 2018; Li \& Zhang, 2003). On the other hand, Britain formulated The Public Health Act because of the cholera in the 19th century, hoping to improve the urban environment and promote public health by regulating street space and guaranteeing drainage and other infrastructure construction. The plague of 1894 led to the introduction of The Hong Kong Public Health and Building Ordinance, which stipulated the area of open space in buildings and the width of streets. In 2005, after the SARS outbreak, China issued and implemented The National General Emergency Plan for Public Emergencies, which made detailed provisions on various emergency measures in the process of handling public health emergencies. It is these constant reflections after disasters that guide the healthier development of 
cities and also promote the birth of urban planning in the modern sense (Li \& Hou, 2020).

The relationship between urban planning and major epidemics has brought great challenges to urban spatial planning and governance. The outbreak and spread of the epidemic is a process of space-time evolution and human-landspace interaction ( $\mathrm{Li}$ et al., 2020a). Understanding the evolution and development rules of the epidemic in different scales such as regions, cities, and communities is an important decision-making basis for urban planning in dealing with major epidemic prevention and control (Chen et al., 2021). For disease research at the large regional level, Eisen, $\mathrm{L}$ et al. discussed how to use GIS to prevent and control diseases such as malaria and West Nile virus (Eisen \& Eisen, 2011). At the urban spatial scale, Cao Zhidong et al. used the disease thematic map to describe the spatial pattern and differentiation characteristics of SARS cases in Guangzhou and provided a scientific basis for public health emergency plans (Cao et al., 2008).

Now, there are few discussions on the spatiotemporal evolution and distribution of COVID-19 epidemic in China and there is no systematic study. What more comprehensive is that $\mathrm{Li}, \mathrm{G}$. used spatial analysis method to explore the spatiotemporal evolution process of COVID-19 epidemic in China from four spatial scales of province, city, county and community (Li et al., 2020a). At the provincial and municipal spatial level, Li Qingqing et al. explored the migration of the trajectory of the epidemic gravity center and its influencing factors through the spatial epidemiological analysis of the epidemic in Guangdong Province ( $\mathrm{Li}$ et al., 2020b). Zhu Yong et al. and Chen Xiao et al. conducted relevant analysis and demonstration on the evolution of spatial distribution pattern, clustering characteristics, and influencing factors of the COVID-19 epidemic in Chongqing (Zhu et al., 2021; Chen et al., 2020). Jin Annan et al. found out the epidemic spread mode dominated by "linear" migration in Shenzhen, and proposed the prevention and control theory under the mutual feed and cooperation of "time-spacehuman" (Jin et al., 2020). In addition, transmission dynamics constructs corresponding models based on the history and current situation of the epidemic to predict the future trend. For example, Zhou Tao et al. and Xiong et al. found in their studies that the isolation rate and intervention policies have a great impact on the transmission of the virus (Zhou et al., 2020; Hao \& Yan, 2020).

At present, researches on the spread and distribution of the epidemic in $\mathrm{Wu}$ han mainly focus on the urban spatial scale. For example, Li Xin et al. explained and performed the actual situation and mechanism of the occurrence, transmission, and diffusion of the epidemic in the urban space of Wuhan based on the microblog data from the four indicators of social population, Urban Morphology, urban facilities, and urban function. Ma Yiwen et al. studied the relationship between residential space characteristics and the occurrence and development of the epidemic from the scale of residential communities within the Third Ring 
Road in Wuhan (Li et al., 2020c; Ma et al., 2020). Zhou Wei focused on the community with a high epidemic incidence in Hankou from the perspective of the urban built environment, carried out a study on the spatial correlation of communities affecting the epidemic with 15-minute living circles (Zhou, 2020). Another important research direction in this field is to analyze the spread of the epidemic from a geographical perspective (Zhang et al., 2020).

In addition to the study on the spatial distribution characteristics of the epidemic, Ye Zhongnan derived the community unit model of urban epidemic transmission for the epidemic in the central urban area of Wuhan, revealing the process of epidemic transmission and diffusion, and effectively simulating the impact of public health interventions on the development of the epidemic (Ye, 2020).

The mainstream of previous studies on the spatiotemporal distribution of COVID-19 outbreaks were the analysis of distribution characteristics at the provincial, municipal, and district scales combined with epidemiology, deduction of the transmission evolution process, and evaluation of epidemic prevention and control intervention measures (Chen et al., 2021). However, there are relatively few epidemics that focus on the scale of urban communities. The epidemic prevention experience in the past year or more tells us that epidemic prevention and control must not only involve regional closure and joint prevention at the city level, but also in-depth control and isolation prevention and control at the community and building level. Only by interlocking the epidemic prevention systems from large to small, can we deal with sudden and major epidemics more comprehensively and systematically, and promote the healthy development of cities.

Therefore, starting from the space of the community, this study takes the epidemic community in the main urban area of Wuhan as the research object. Based on the epidemic data of Wuhan, the relevant POI data of the city, and the planning data of the community, the study discusses the spatial distribution characteristics and relevant influencing factors of the epidemic and reveals the relevant transmission law and action mechanism. The aim is to provide suggestions for the prevention and control of urban public health events and the spatial planning and governance of residential areas in the post-epidemic and re-epidemic eras.

\section{Study Foundation}

\subsection{Study Area}

As the epicenter of the outbreak in China, Wuhan was relatively concentrated in the early stage of virus transmission, mainly distributed in the main urban areas with frequent activities. We made a preliminary determination of the distribution data of each district, and found that the density of the epidemic in the peripheral urban areas of Wuhan differs significantly from that in the main urban areas. To make the study more representative and accurate, this study takes the main urban 
area of Wuhan, which is composed of seven administrative regions, as the research area. As of the end of 2019, Wuhan's main urban areas included Jianghan Districts, Hanyang Districts, Jiangan Districts, Hongshan Districts, Wuchang Districts, Qingshan Districts, and Qiaokou Districts (Figure 1). The main urban area is 863 square kilometers, and the built-up area is 552.61 square kilometers.

\subsection{Research Data and Sources}

\subsubsection{Epidemic Data of Wuhan Community}

According to a notice issued by the Wuhan Municipal Health Commission, the period from late January to late February 2020 is the most severe period of COVID-19 and the fastest increase in cases in Wuhan. The epidemic spread mainly through natural transmission, and the degree of intervention by public intervention policies on confirmed cases is relatively low. Since the official website did not release the corresponding announcements specific to each community, this study made statistics on the news of the epidemic in each community in Wuhan through the WeChat account (Zhongbei Road) ${ }^{1}$. In this study, the total number of cumulative confirmed and suspected cases in 447 epidemic communities in the main urban area of Wuhan was used as the total number of cases in each community. And the coordinates of the data are matched by the address information. In order to verify that the content of the WeChat public account is consistent with the regional distribution, and that the data is authentic and representative, a fitting comparison was made between the epidemic data and the cumulative number of confirmed cases in each administrative region released by the Wuhan Healthcare Commission (Table 1). As shown in the table, Pearson chisquare value was 156 , and the significance $\mathrm{P}$-value was $0.233(p>0.05)$. There is no significant difference. So, the distribution of epidemic data in the community is reasonable.
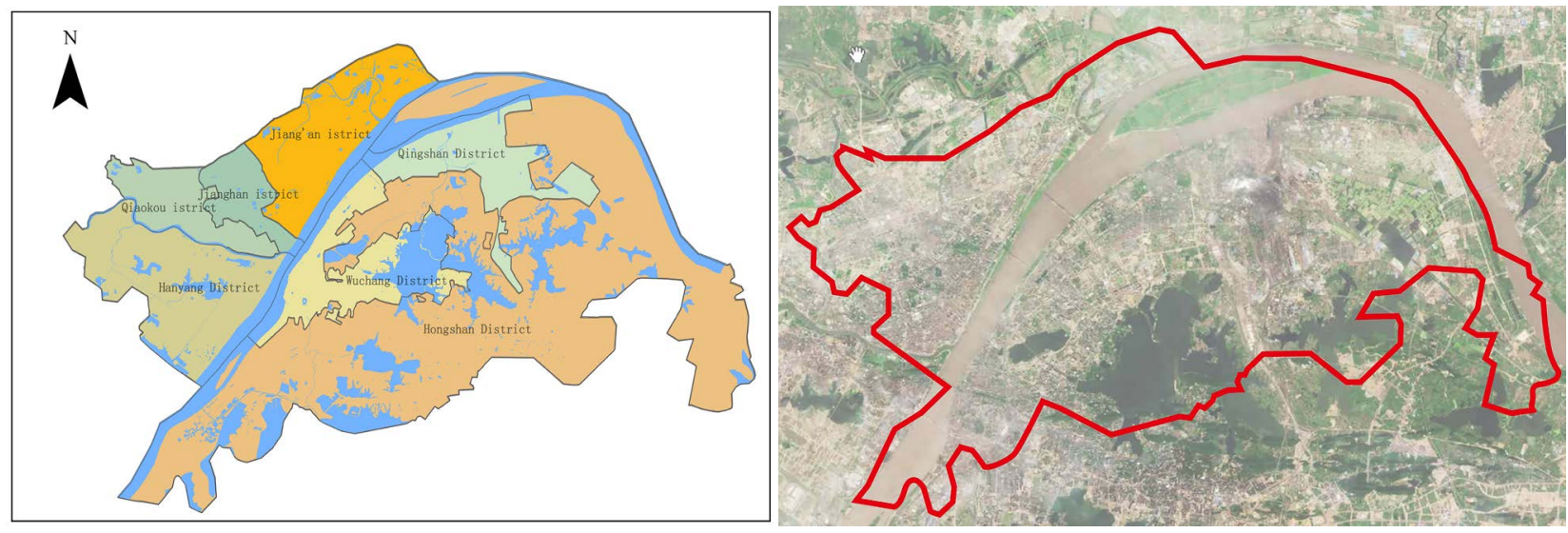

Figure 1. Research scope.

${ }^{1}$ Zhongbei Road: this WeChat account mainly releases Wuhan urban construction and other related news. During the COVID-19 outbreak in 2019, the number of confirmed patients in Wuhan was collected and updated in real-time. This paper collected and analyzed the results later to demonstrate their rationality. 
Table 1. Chi-square distribution test of epidemic data.

\begin{tabular}{|c|c|c|c|c|c|c|c|}
\hline Covariance Item & Jiang'an District & Jianghan District & $\begin{array}{l}\text { Qiaokou } \\
\text { District }\end{array}$ & $\begin{array}{l}\text { Hanyang } \\
\text { District }\end{array}$ & $\begin{array}{l}\text { Wuchang } \\
\text { District }\end{array}$ & $\begin{array}{l}\text { Qingshan } \\
\text { District }\end{array}$ & $\begin{array}{c}\text { Hongshan } \\
\text { District }\end{array}$ \\
\hline Official notification & 4239 & 7227 & 6757 & 3514 & 8032 & 2924 & 4784 \\
\hline WeChat statistics & 1267 & 1327 & 1129 & 2200 & 1994 & 1721 & 4195 \\
\hline $\begin{array}{c}\text { Pearson } \\
\text { chi-square }\end{array}$ & \multicolumn{7}{|c|}{156} \\
\hline $\begin{array}{c}\text { Significance } \\
\text { P-value }\end{array}$ & \multicolumn{7}{|c|}{0.233} \\
\hline
\end{tabular}

\subsubsection{Community Internal Planning Indicator Data}

We searched the relevant planning information of the residential community until December 2020 through the Internet housing data website, Baidu map, and Amap. There are a total of 10 indicators, including land use scale, base area, floor area ratio, building density, building height, building spacing, number of buildings, number of households, green space rate, and completion time.

\subsubsection{POI Data of Supporting Facilities near the Community}

According to the relevant characteristics of infectious diseases, the layout of urban open space and traffic nodes to a large extent affects the spatial distribution of the epidemic (Niu et al., 2021). Therefore, this study obtained the population data of various streets in Wuhan from the Urban Data Party website (2019) and got the POI statistics of the distribution of public transportation and subway stations, commercial service facilities, and large general hospitals near the community through Baidu Map API (2020).

In Figure 2, Figure (a) shows the population data distribution of each street in the main urban area. There are 93 streets in the main urban area. Figure (b) shows the distribution of public transportation stations (subway and bus), with 2259 major transportation stations. Figure (c) is the distribution map of commercial facilities composed of a large commercial complex, residential commercial area, and main businesses along the street. We counted 32,907 points of business points of interest. Figure (d) shows the distribution of 2539 hospitals (including general hospitals at city and district levels, specialized hospitals, and other hospitals with better facilities). The distribution of these four kinds of interest points is mainly distributed along the axis, and the distribution is dense along the Changjiang River and Luoyu Road to Guanggu area. Meanwhile, the distribution is divergent and decreasing from both sides of the Changiiang River to the outer circle layer, and the distribution density of the north bank of Changjiang River is larger than the south bank of Changjiang River.

\subsection{Research Methods}

\subsubsection{Spatial Autocorrelation}

Spatial autocorrelation refers to the potential interdependence of observed data 


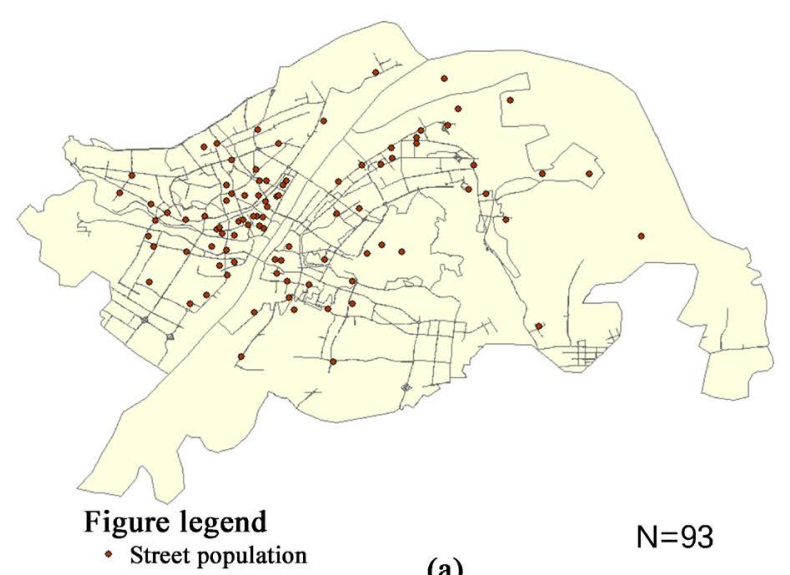

- Street population

(a)

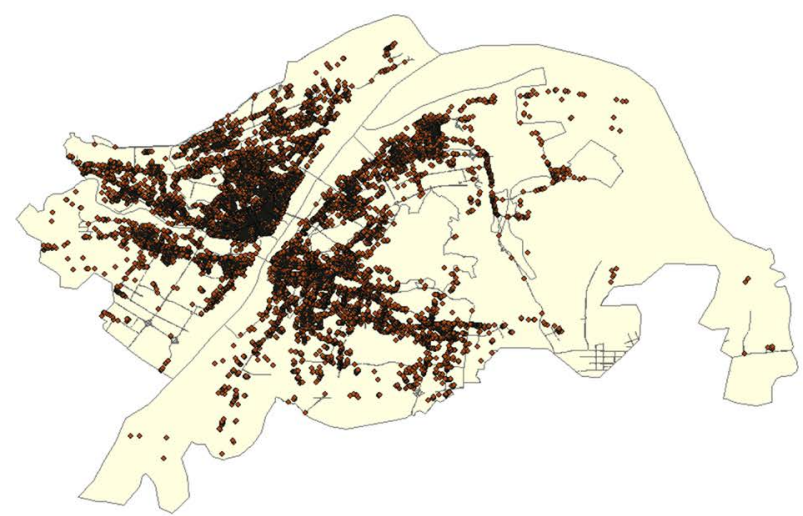

Figure legend

- Commercial

(c)

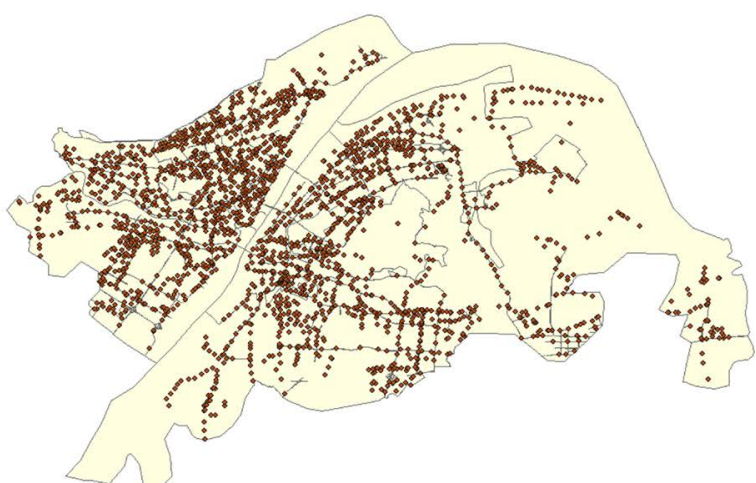

Figure legend

Public transportaion stations

$N=2259$

(b)

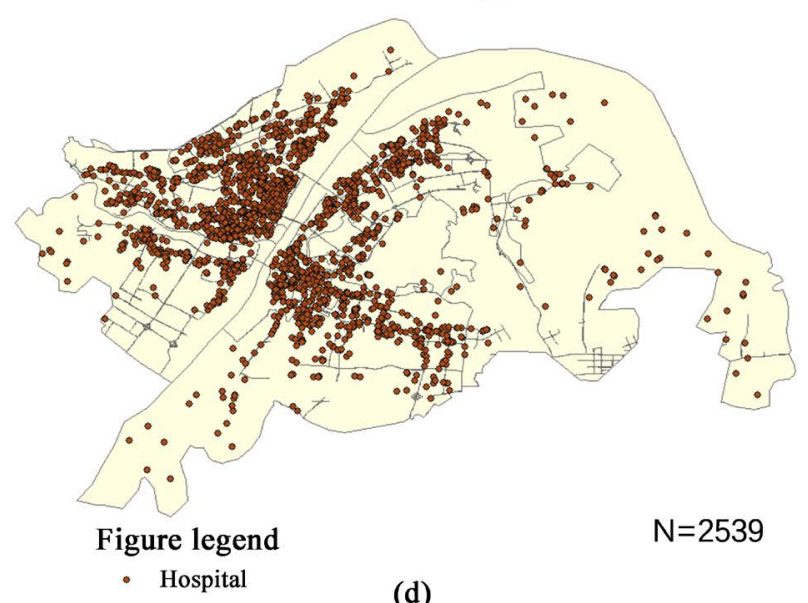

(d)

Figure 2. POI data distribution.

of some variables within the same distribution area. Tobler's First Law of Geography states that everything is related to everything else, but close things are more related than things that are far away (Tobler, 1970). In this study, the global spatial autocorrelation analysis (Moran I) of the ArcGIS10.5 spatial statistical tool was used to measure the overall spatial distribution of the epidemic data of 447 communities, to find out the clustering characteristics of the epidemic situation in the urban space within the research scope. In terms of Local measurement, clustering and outlier analysis (Anselin Local Moran I) under the clustering distribution mapping mode of spatial statistical tools was used to explore the specific spatial distribution locations of communities with different epidemic densities.

\subsubsection{Getis-Ord Gi*}

It is mainly used for spatial clustering of high value (hot spot) and low value (cold spot) with statistical significance. In this study, the distribution law of cold and hot spots in the main urban area of the epidemic was analyzed by the Getis-Ord $\mathrm{Gi}^{\star}$ under the clustering distribution mapping model of ArcGIS10.5 spatial statistical tool. 


\subsubsection{Principal Component Analysis}

Principal component analysis (PCA) is an attempt to recombine the original multiple indicators with certain correlation into a new set of comprehensive indicators, to replace the original ones with the idea of dimension-reduction, to obtain a better subset of variables and interpretation effect. In this study, the SPSS principal component analysis was used to reveal the correlation between the epidemic density and the built environmental factors.

\subsubsection{Multiple Linear Regression}

The change of many urban phenomena is often affected by multiple variables at the same time. Multiple linear regression can be used to study the relationship between change and multiple factors and to find out the specific influence of each factor. In this study, SPSS multiple linear regression analysis was used to reveal the relationship between the built environment factors extracted from dimension reduction and the epidemic density.

\subsection{Research Methods}

The research process and ideas of this paper mainly include three steps, which are as follows and Figure 3.

1) The spatial distribution of the epidemic area data was studied to obtain the regional agglomeration effect and the distribution of cold and hot spots.

2) Description of the spatial distribution of the index factors of the cell, combining the various index factors with the spatial geographical location of the cell, and unifying the analysis scale of each factor from the space.

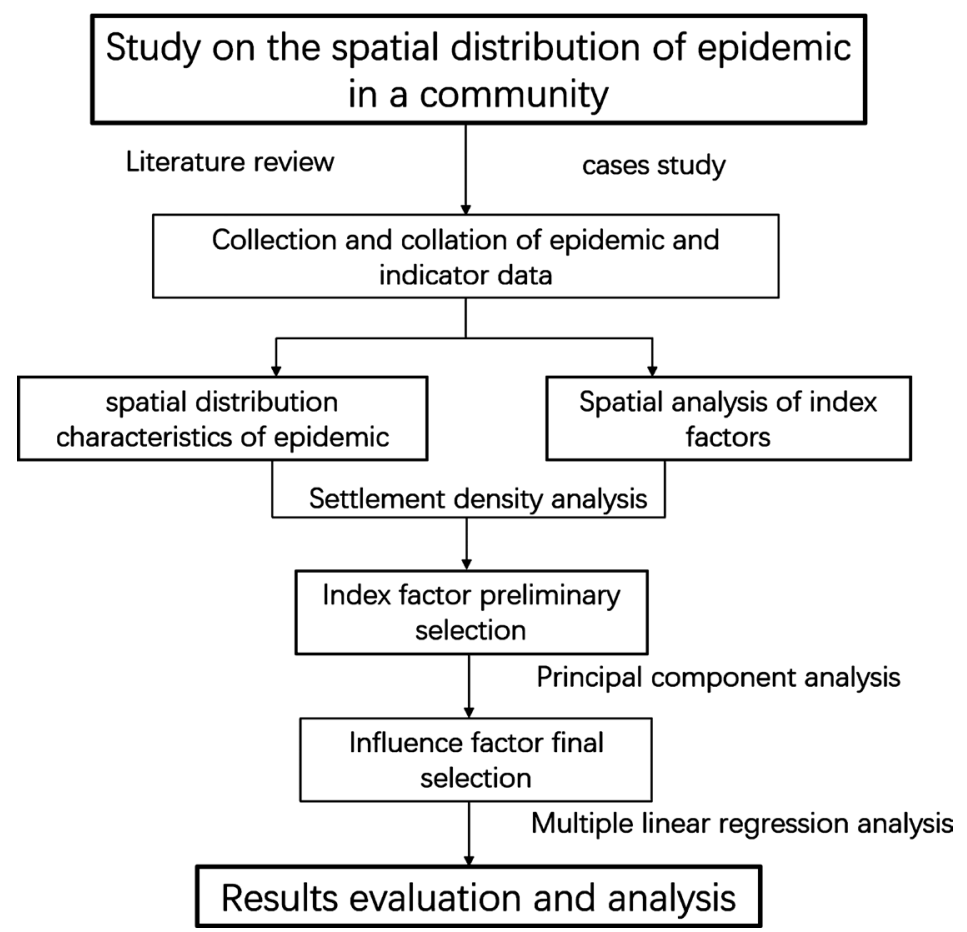

Figure 3. Research flow chart. 
3) Correlation analysis. a) Pearson correlation tests were performed on the primary screening indicators to determine the correlation between each indicator and epidemic density. b) Using principal component analysis and multiple linear regression analysis to explore the influence and direction of each principal component factor on the epidemic.

\section{Analysis of Spatial Distribution Characteristics of Epidemic Communities}

\subsection{Description of the Spatial Distribution of the Epidemic}

As of February 26, 2020, among the 447 affected communities in Wuhan, the average number of cases in the communities was 15.92. And the highest number of cases in the communities was 139 and the lowest was 1, and the standard deviation was about 16.832. Based on kernel density estimation (KDE), the average epidemic density at the community level in Wuhan was 2.92 people/ha, with a standard deviation of 4.99 .

According to the natural breakpoint classification method, the core density of 447 epidemic communities was divided into 9 layers (Figure 4). The distribution

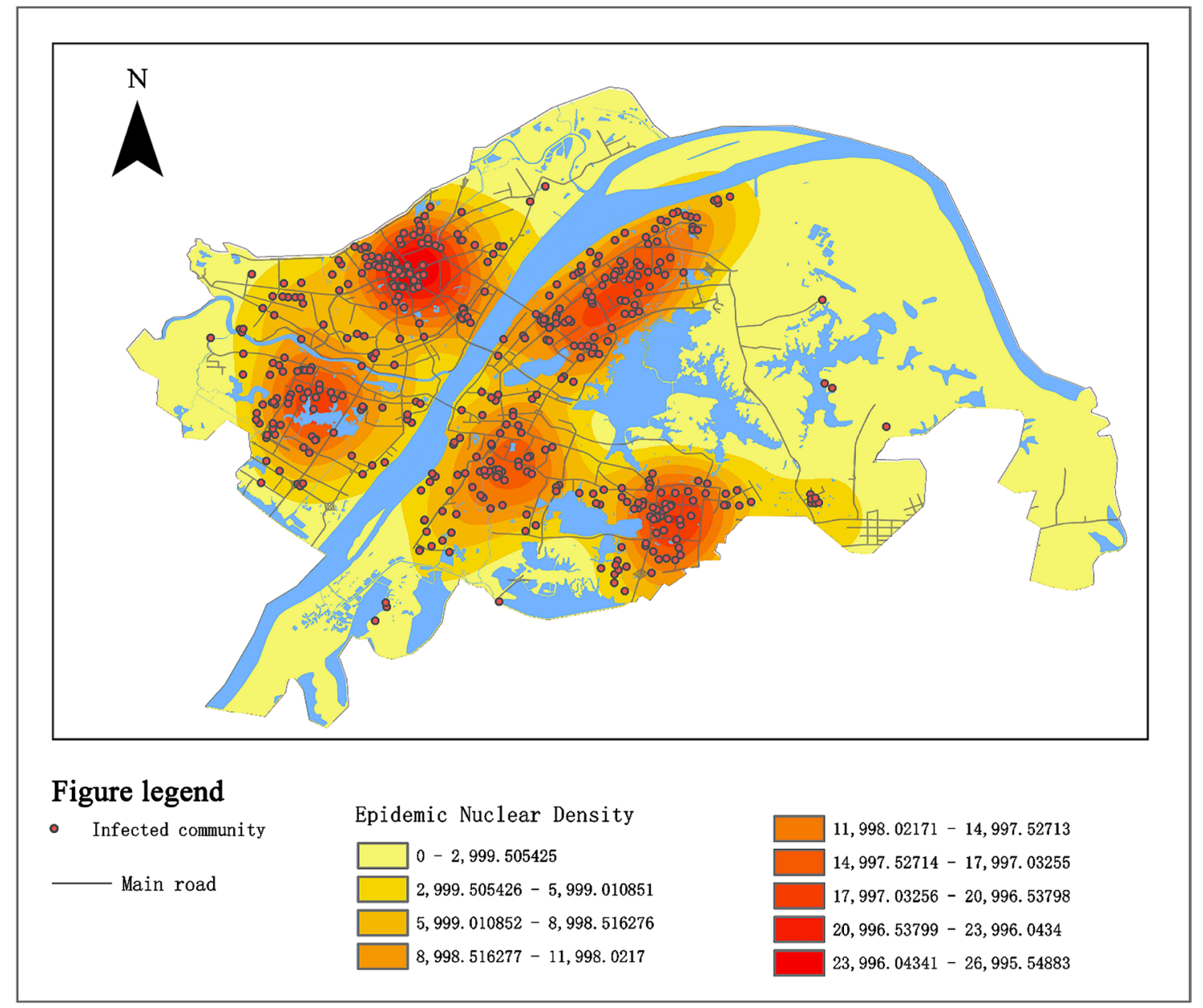

Figure 4. Distribution map of epidemic nuclear density. 
of epidemic com-munities in the study area presented a hierarchical pattern of spreading from the center to the outside. The epidemic communities were mainly distributed within the third ring road and divided by rivers and lakes into a spatial pattern of "One Belt, Three Core". "One Belt" refers to the Wuchang-Qingshan high epidemic density coastal zone on the south bank of the Yangtze River, and "Three Core" refers to the three high epidemic density areas formed by the Yangtze River and the Han River, with Jianghan District, Hanyang District and Hongshan District as the core respectively. In addition, due to the influence of the tourism location of East Lake, the epidemic distribution in Hongshan District developed into an epidemic area around the lake.

\subsection{Spatial Autocorrelation Characteristics of the Epidemic}

Kernel density analysis has been used to determine the distribution density of the epidemic communities, and global spatial autocorrelation reveals the spatial clustering types of the epidemic communities (Figure 5(a)), indicating that it has significant spatial autocorrelation (Moran index is $0.598, \mathrm{Z}$ value is 4.023 ,

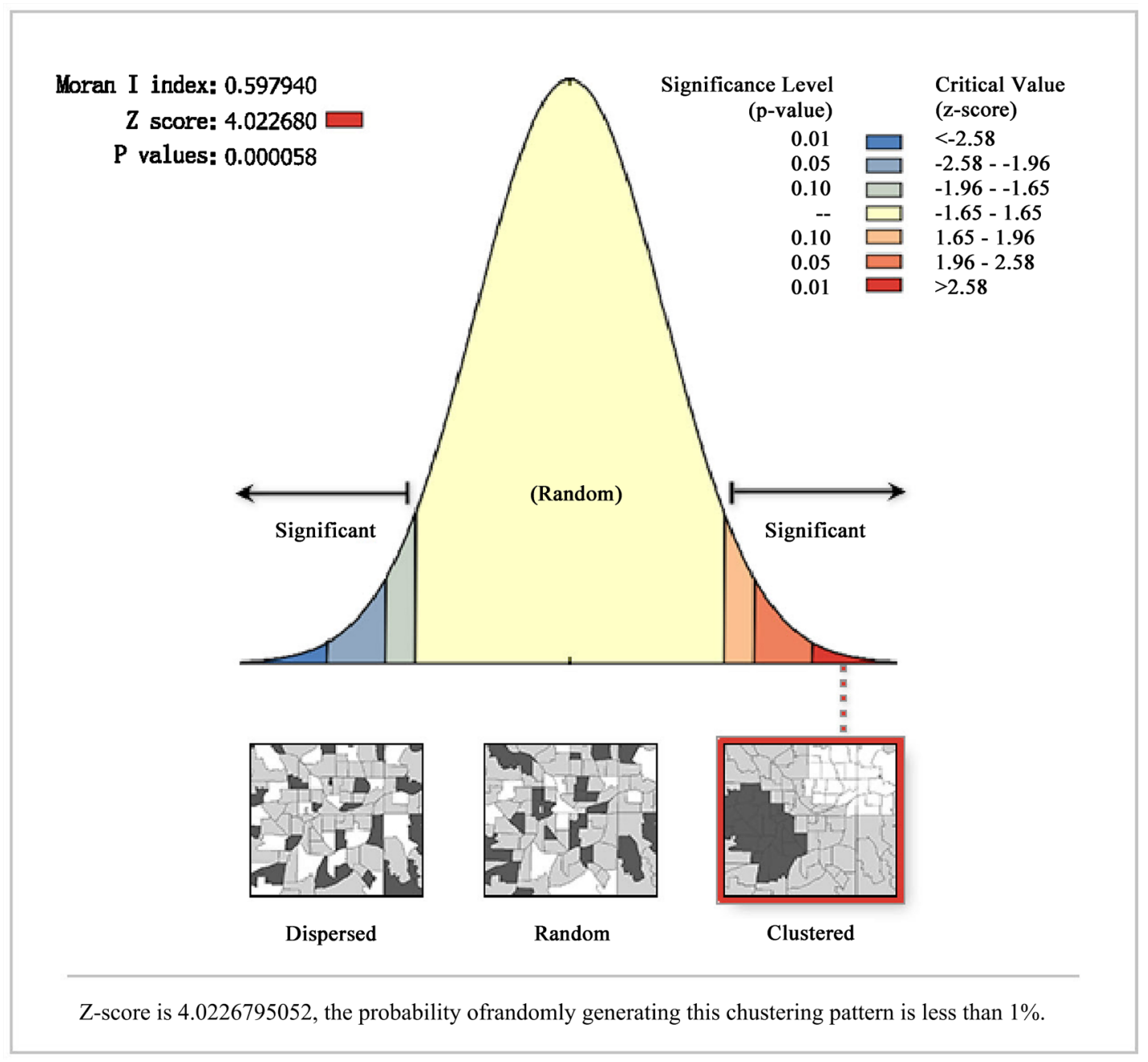

(a) 


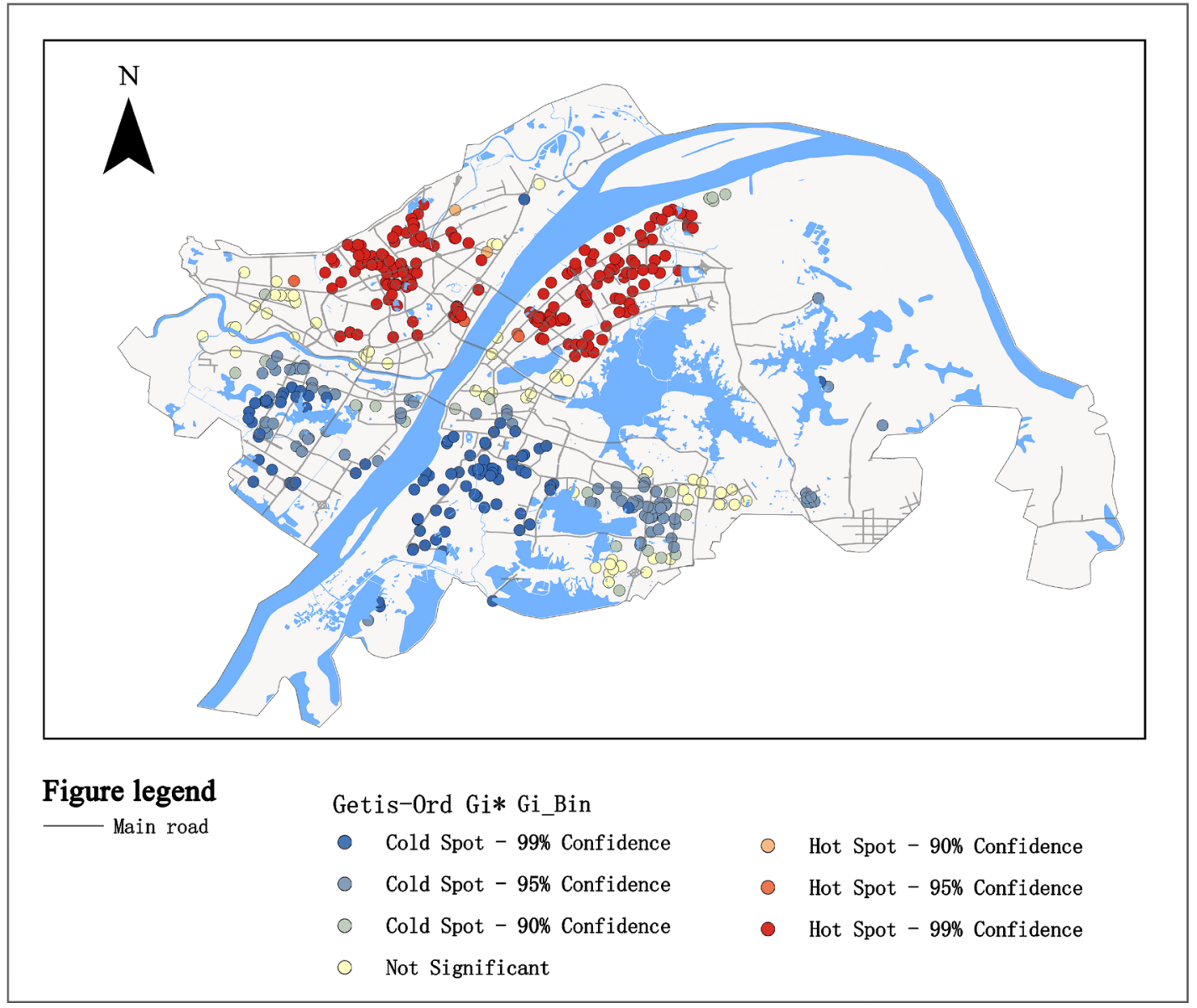

(b)

Figure 5. Spatial autocorrelation analysis. (a) Global spatial autocorrelation analysis (Moran I); (b) Local spatial autocorrelation analysis (Anselin Local Moran I).

and the probability of random generation of this clustering pattern is less than $1 \%)$. According to the discussion of Anselin, under the condition of spatial clustering, if a community is a high-density infected area, then it is mostly surrounded by high-density epidemic communities, or a low-density epidemic community is mostly surrounded by low-density communities (Anselin \& Getis, 2010). The results of clustering and outlier analysis (Figure 5(b)) were basically consistent with the kernel density estimates. High aggregation areas are mainly distributed in the north of Jianghan District, Hanyang District and Wuchang District along the Yangtze River and then spread to the periphery. Jianghan and Hanyang are the main parts of the main urban area of Wuhan City, with high development intensity, high population density and dense stream of people, and are greatly affected by the epidemic. Hongshan District is a concentrated area of colleges and universities. During the epidemic period, most college students had left Wuhan. With the barrier effect of natural geography, rivers and water areas, the epidemic density was mainly low aggregation. The high and low aggregation distribution of the epidemic communities in the city area is obvious, which reflects the Geo- 
spatial proximity characteristics of infectious diseases.

\subsection{Distribution Characteristics of Cold and Hot Spots}

In-depth exploration of the hot spots where the epidemic occurred will help to further explore the law of epidemic transmission and evolution. Hotspot analysis shows that the hotspots with a 99\% confidence level are located in Jianghan District, Jiangan District, Qi-aokou District and the north of Wuchang District. At the edges of these regions, there are mainly hot spots and insignificant cold and hot areas with $95 \%$ and $90 \%$ confidence levels. Cold spots with a confidence level of $99 \%$ were found in the south of Hanyang District and the south of Hongshan District. The cold and hot spots are more intuitive than cluster analysis to show the occurrence probability of epidemics in space (Figure 6).

\section{Index Factor Analysis Process}

\subsection{Spatial Distribution Analysis of Various Environmental Factors}

\subsubsection{Spatial Distribution of Physical and Environmental Indicators in} the Community

The description of 10 physical spatial environmental indicators of 447 epidemic

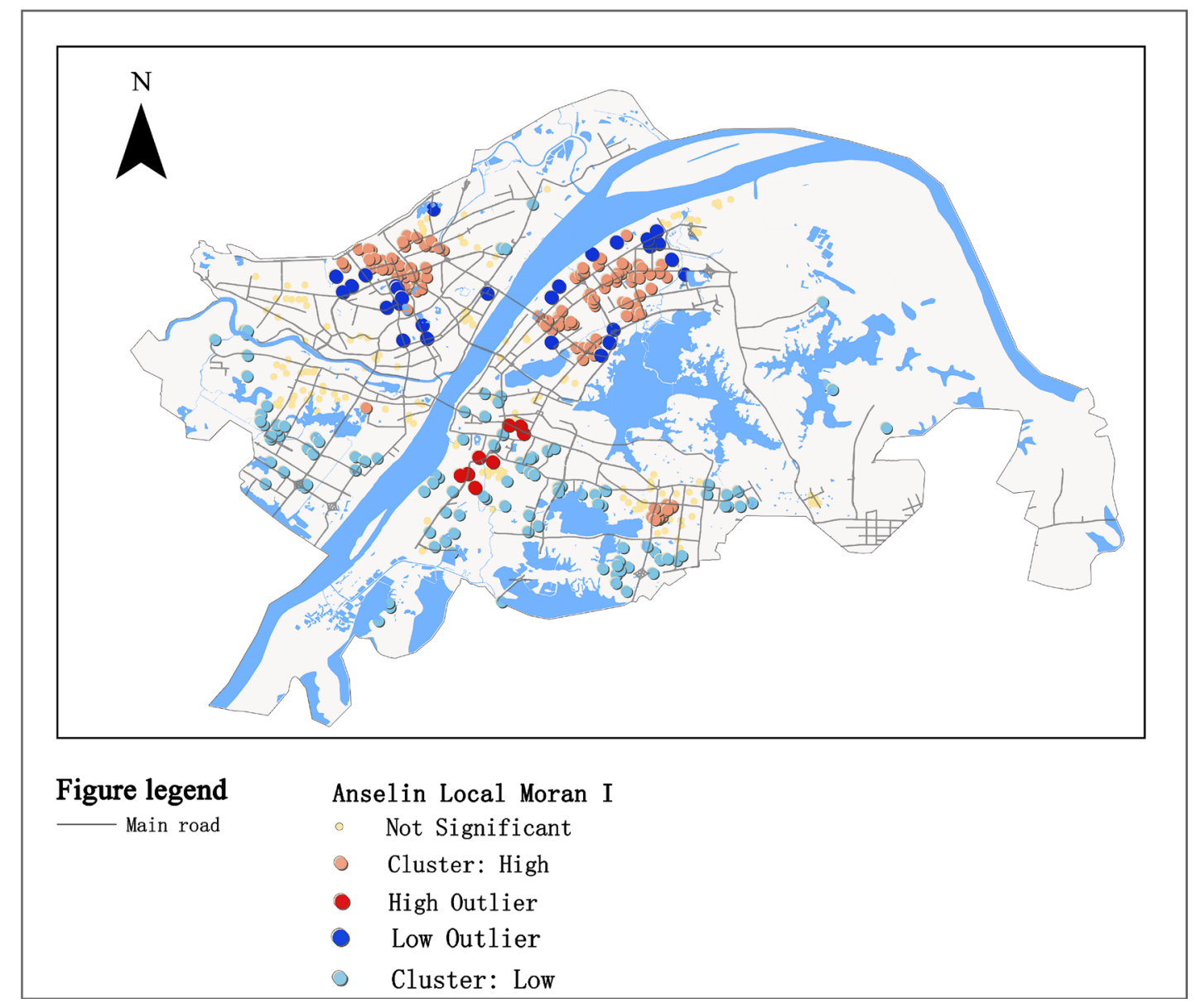

Figure 6. Analysis of cold and hot spots. 
com-munities is as follows: the average base area is $17,584.66 \mathrm{~m}^{2}$, the average land area is $73,965 \mathrm{~m}^{2}$, the size of the community is medium; the average number of buildings is 18.16; the average number of households is 1574; the average plot ratio is 2.819; the average building density is 0.2653 ; the average building height is $47.43 \mathrm{~m}$, about 16 floors (calculated by 3 meters per floor), belongs to the high-rise residence, and the average building spacing is $31.7 \mathrm{~m}$; the average greening rate is $34 \%$, and the average completion time is 2007 .

As shown in Figure 7, the spatial distribution of the spatial physical environmental in-dicators of the community shows no obvious relationship between the spatial distribution of building base area, land use area, number of buildings and number of households and the epidemic situation. In the main urban area, the plot size of Jianghan District, Jiangan District and Wuchang District along the river area are small. Generally speaking, the plot base area of the larger land area is larger. The FAR of residential areas within the second ring line on both sides of the Yangtze River is generally higher than that of the peripheral areas. The spatial distribution of building density presents an axis-circle pattern. The residential areas with high building density are mainly concentrated near the riverside axis within the second ring road, while the distribution of building spacing and building density is consistent. The residential areas with high building density have a smaller building spacing. The greenery rate on both sides of the axis along the river is lower than that in the periphery, which is also consistent with the completion time. The greening indicator of the newly built community is higher than that of the old community.

\subsubsection{Spatial Distribution of Supporting Facilities around the Community}

The density values of population density, public transportation stations, commercial facilities and hospitals and other points of interest in each street in the main urban area were connected to the research area to obtain the spatial distribution of various planning factors outside the community, as shown in Figure 8.

The population density of the districts along the north bank of the Yangtze River is generally high, and the high-density population is mainly distributed in Jianghan District, Hanyang District and Wuchang District. The spatial distribution of public transportation stations, businesses, and hospitals around the community are mainly along the axis of the river. The overall density of the north bank of the river is higher than that of the south bank of the river. The density of supporting facilities in the area south of the river from Luoyu Road to Guanggu area is also higher.

\subsection{Analysis of the Relationship between Residential Density and the Epidemic}

Cities will inevitably face the impact of various types of disasters during the growth process. Although the early modern cities in the world caused severe epidemics during the process of urbanization, such as the Black Death in Europe in 


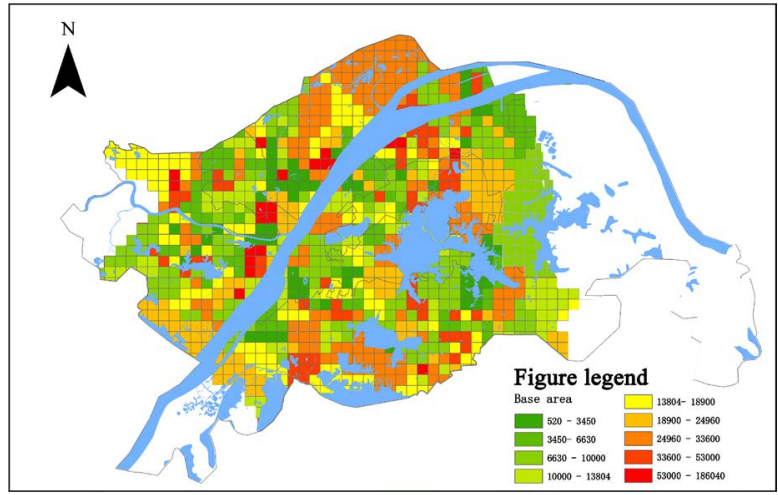

(a)

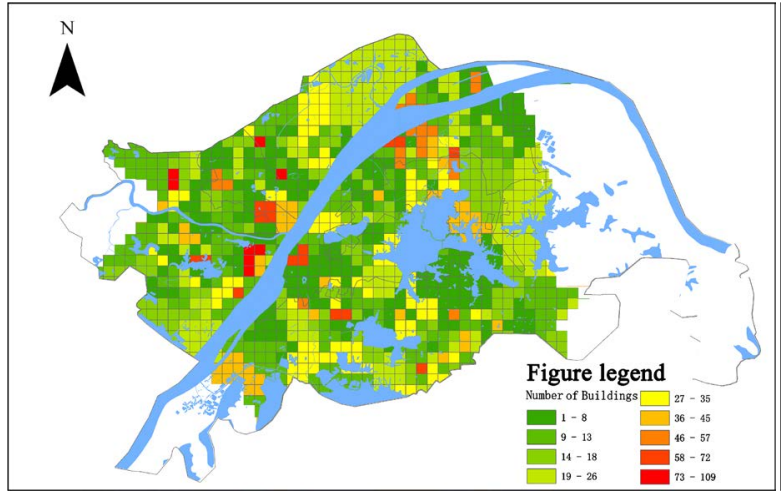

(c)

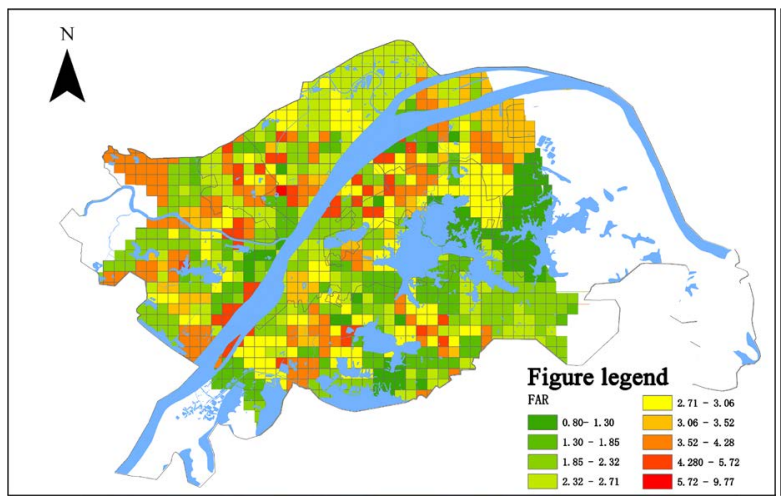

(e)

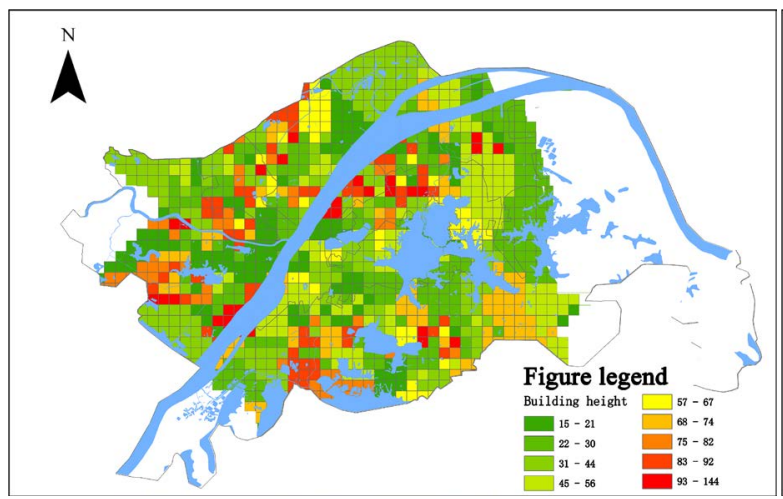

(g)

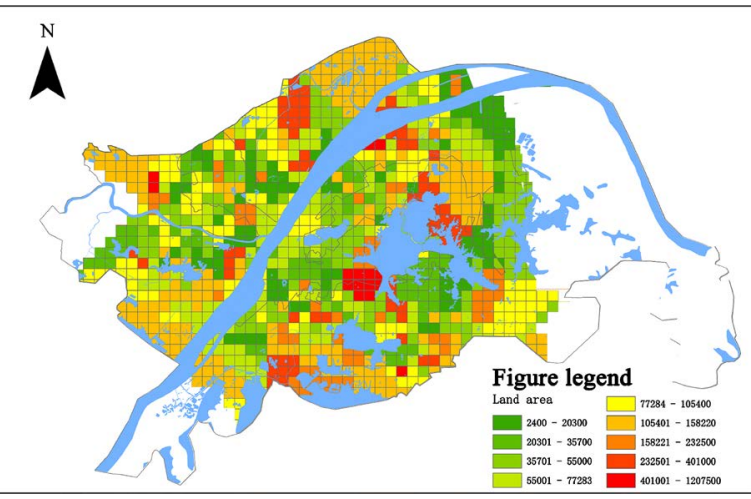

(b)

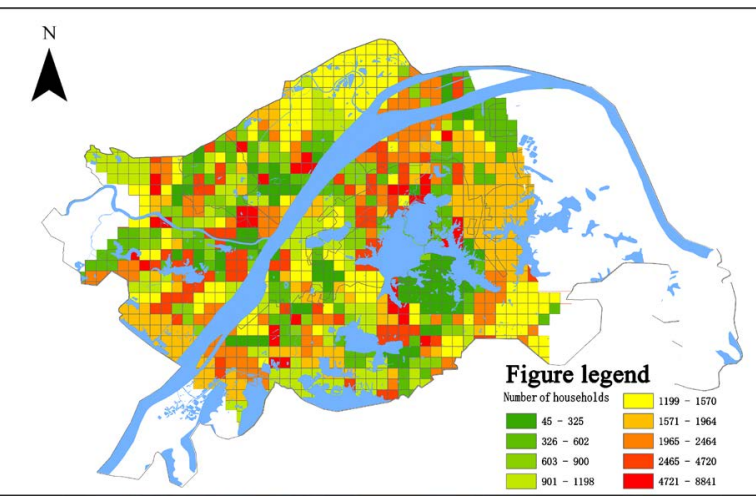

(d)

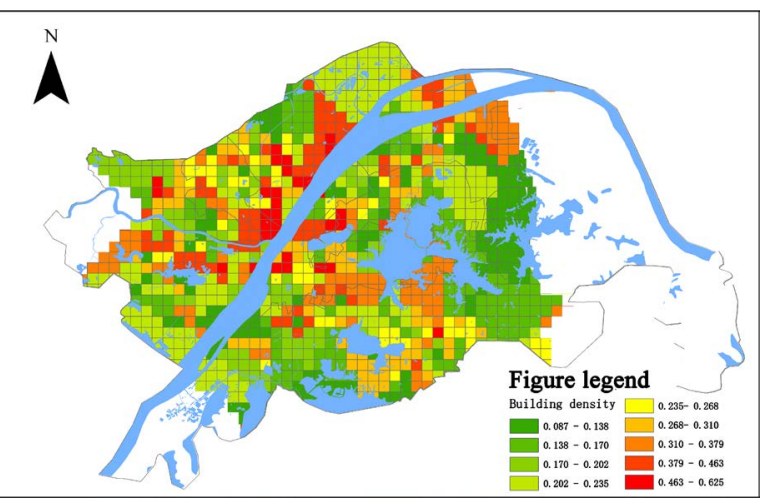

(f)

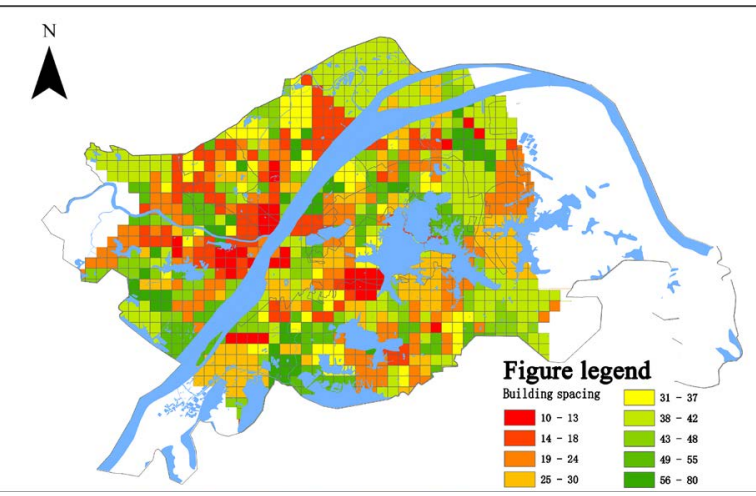

(h) 


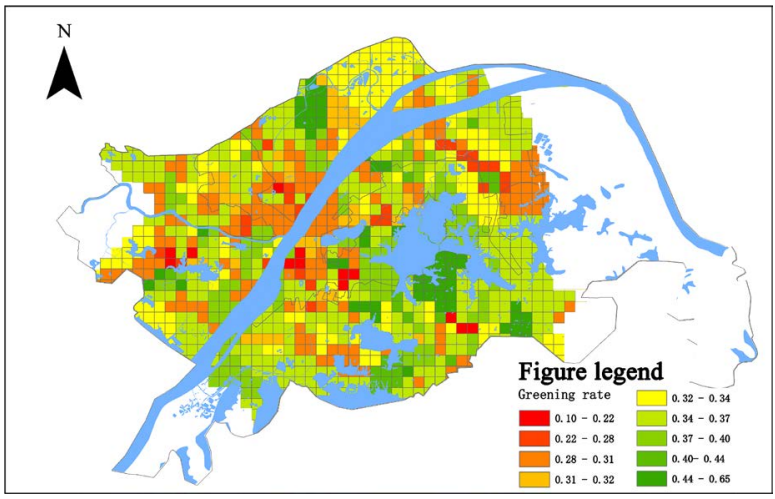

(i)

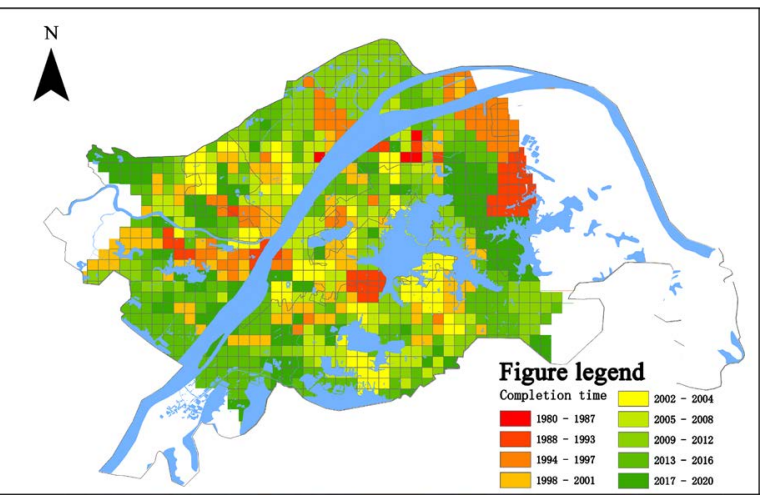

(j)

Figure 7. Spatial distribution of building planning indicators in the community. (a) Base area; (b) Land area; (c) Number of buildings; (d) Number of households; (e) FAR; (f) Building density; (g) Building height; (h) Building spacing; (i) Greening rate; (j) Construction time.

the Middle Ages and the British and French cholera in the $19^{\text {th }}$ century, these public health incidents have promoted the germination of modern urban planning ideas. Urban planning has continued to grow in the process of fighting the epidemic, and the city has not returned to pastoral mode due to choking. Urbanization is the outcome of the development of the social economy and human civilization. Compared with traditional villages, urban intensive land use can reduce the service radius and provide more urban public service content per unit area. It is the embodiment of intensive and optimal allocation of various resources, which is also the fundamental significance of the existence of cities.

China is in a period of rapid urbanization, and the land use pattern is developing from "extensive" to "intensive", but the efficient and intensive land use often leads to the emergence of high-density space, that is, high land intensity and high residential density (Tao, 2020). Regarding the epidemic situation, high residential density is bound to increase the chance of cross-infection and the risk of disease incidence (Dong, 2005; Wang et al., 2021). However, some current studies on COVID-19 have shown that high residential density does not necessarily lead to high epidemic density, which may be due to the improvement of the prevention and control management ability of communities after SARS in China (Zheng \& Liu, 2020; Cao \& Liang, 2020; Zhang \& Lu, 2003; Xue, 2020) and the planning and design of the community itself can support epidemic prevention more scientifically and rationally.

But it is difficult to know the individual transmission routes of specific cases. The population density of the main urban area where the 477 sample communities in this study are located is $13,906.86$ people $/ \mathrm{km}^{2}$, and the average FAR of the communities is 2.819 , which belongs to the urban living space with high population density. Since the research scope of Wang J et al. (Wang et al., 2021) is mostly regional environment, which is different from the object of this study, this paper uses the plot ratio to represent the residential density and carries out correlation analysis with the epidemic density. As can be seen from Table 2, the 


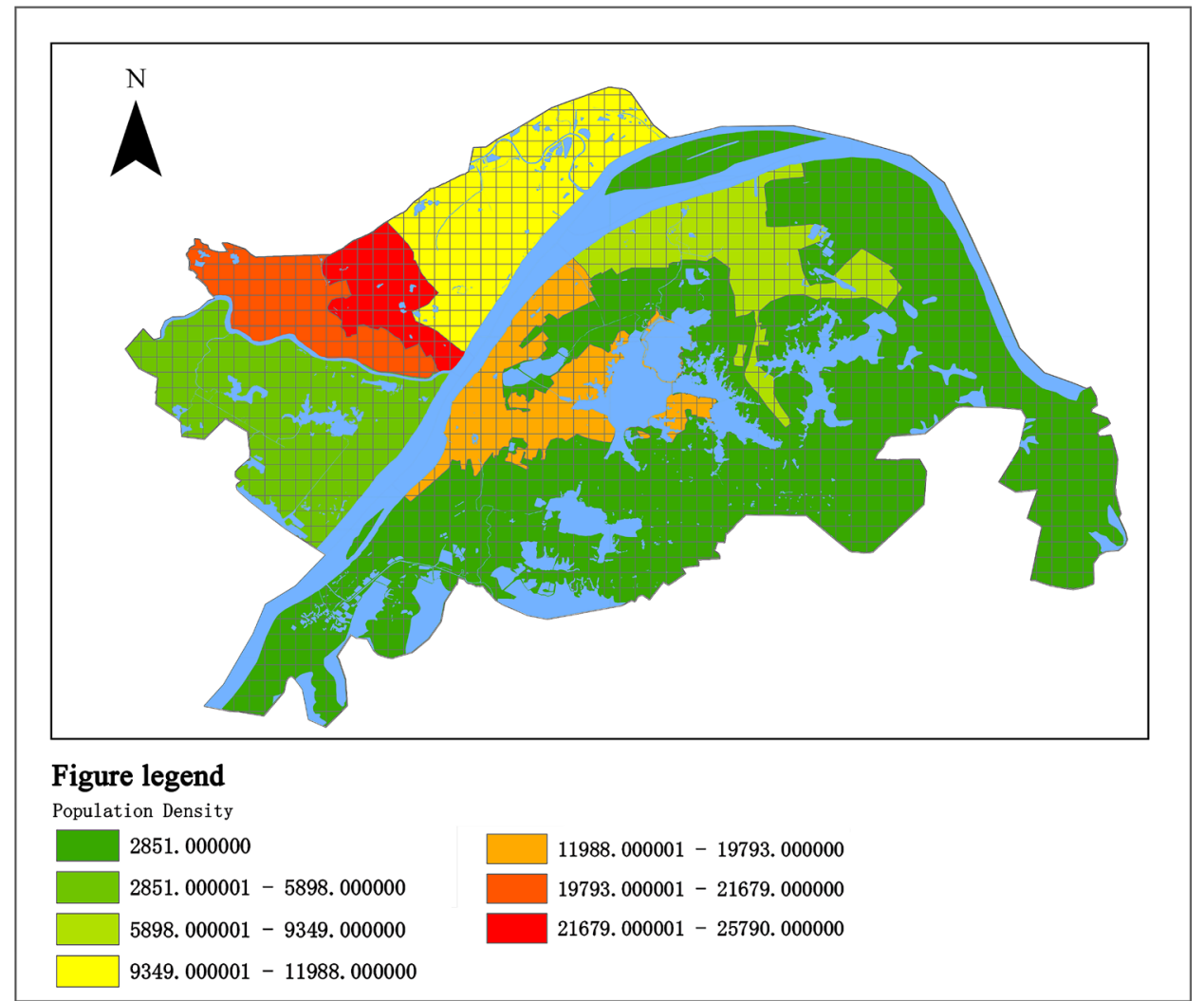

(a)

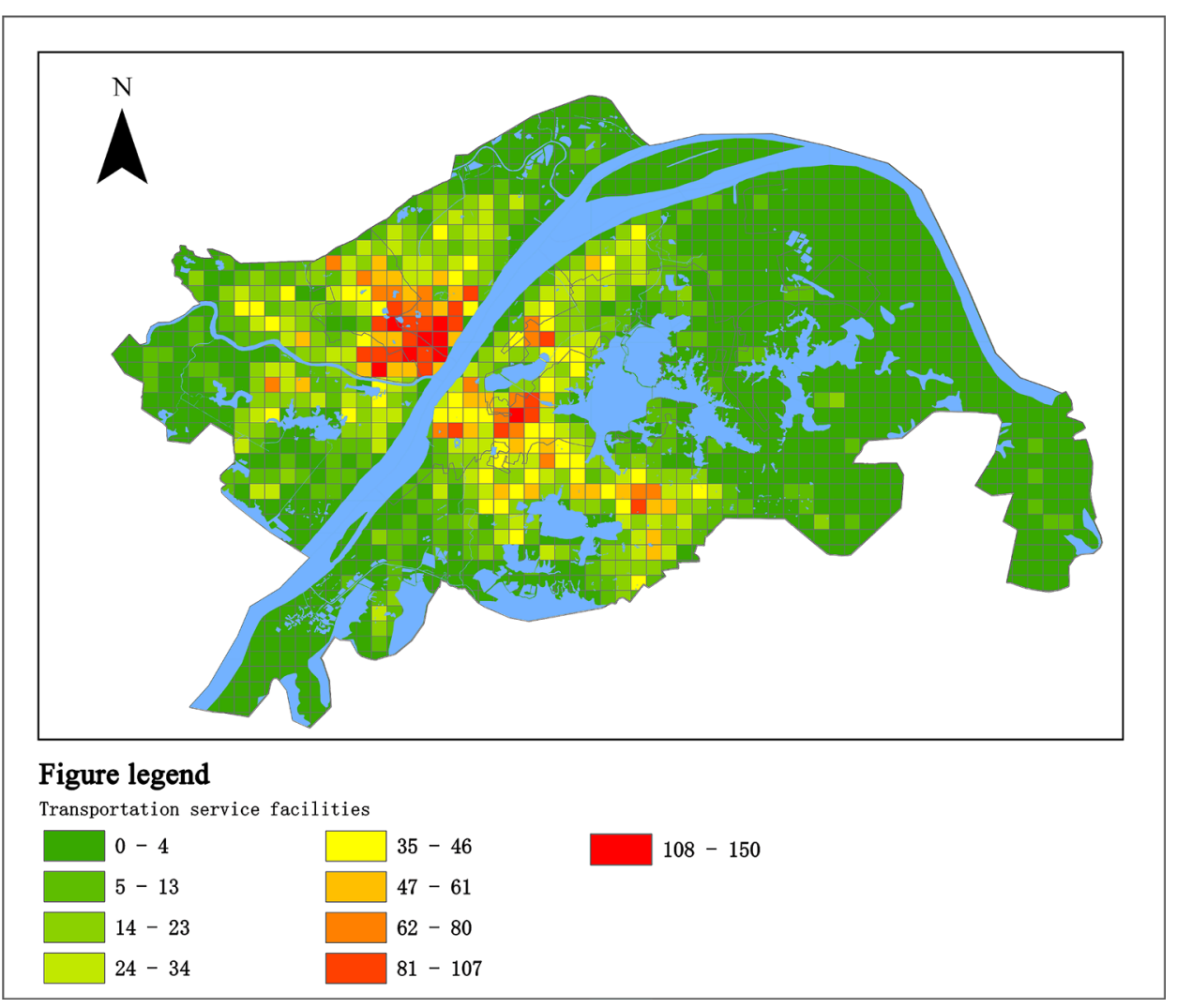

(b) 


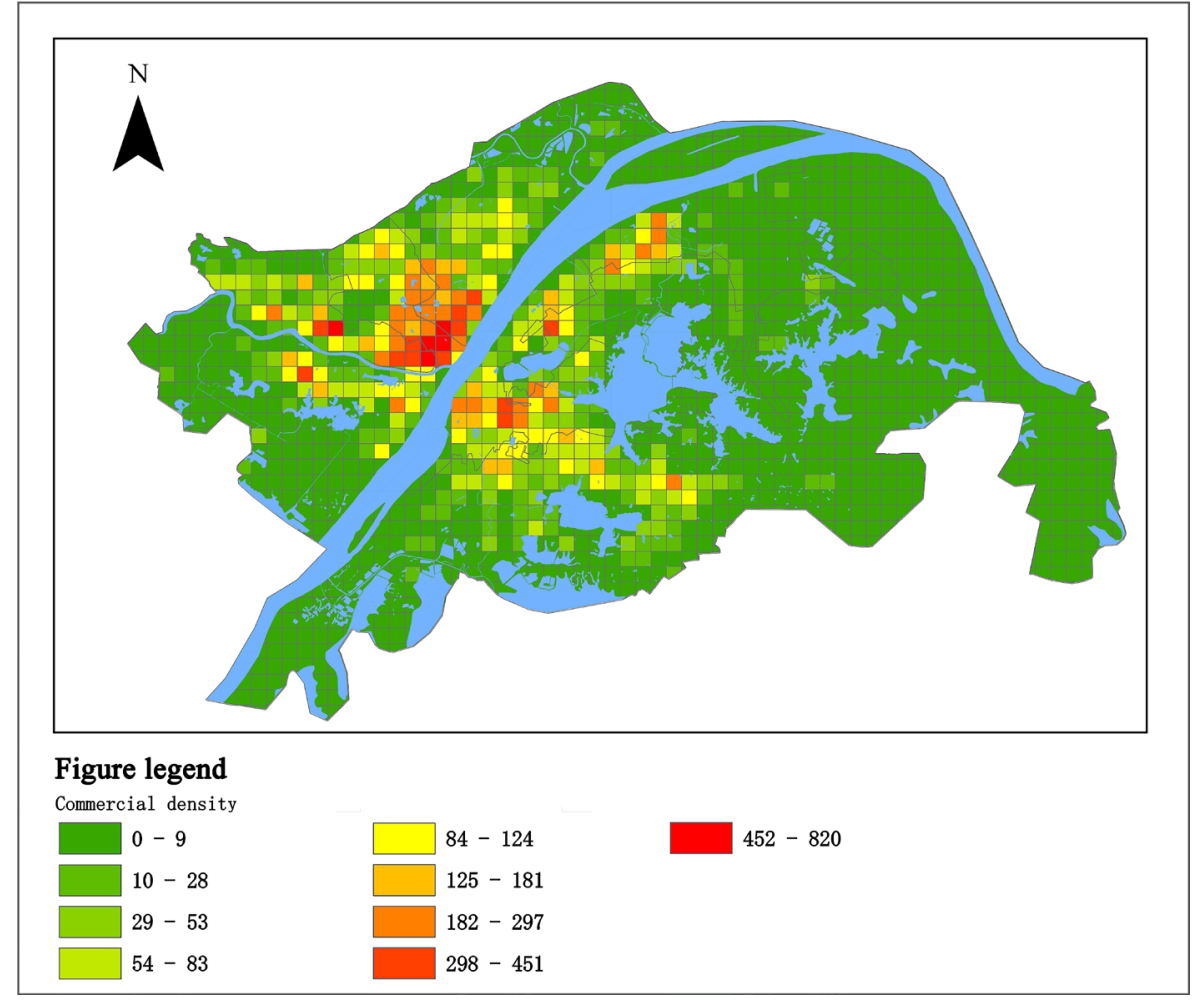

(c)

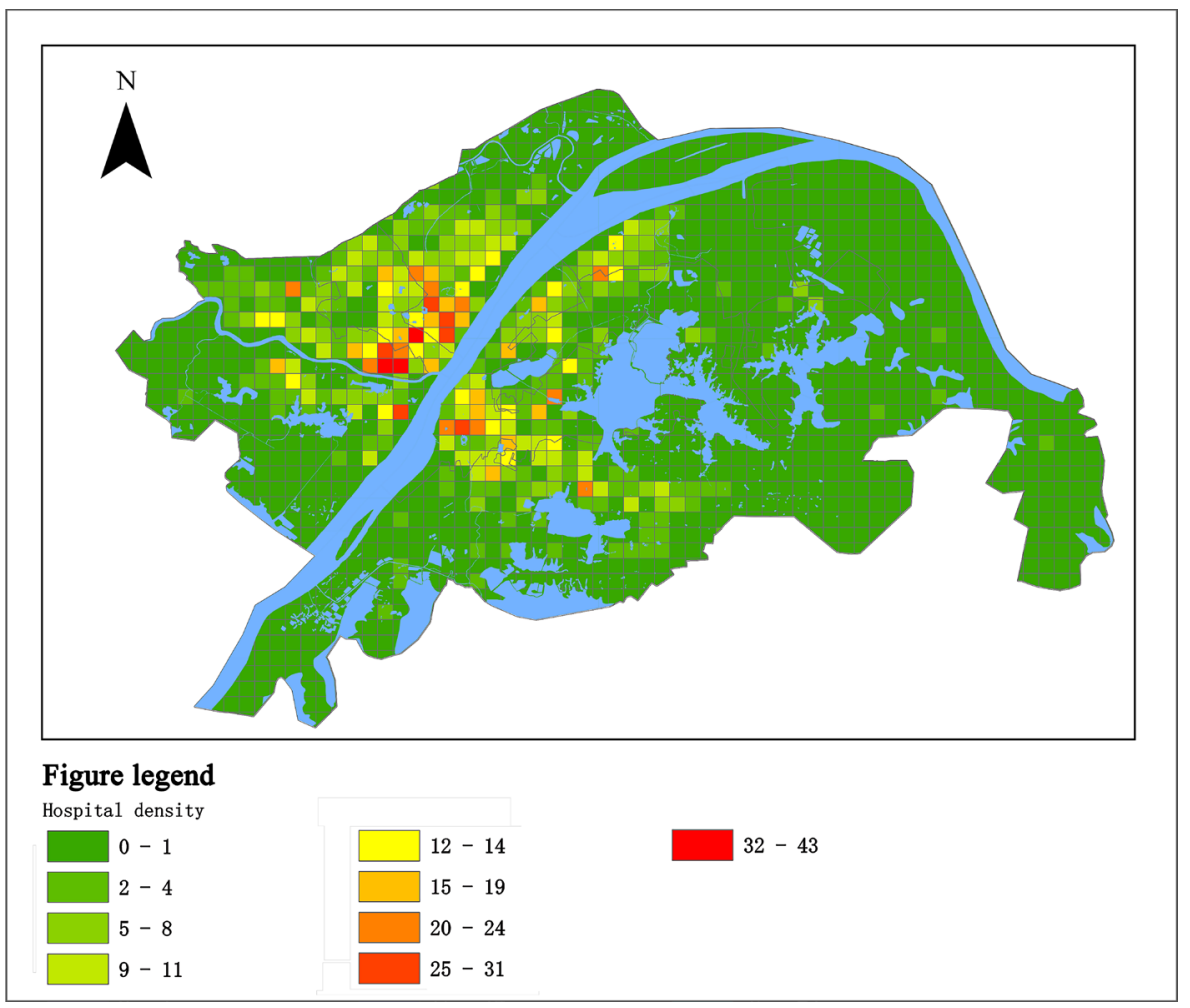

(d)

Figure 8. Spatial distribution of supporting facilities around the community. (a) Population density; (b) Public transport stations; (c) Commercial facilities; (d) Hospital care. 
Table 2. Correlation coefficient.

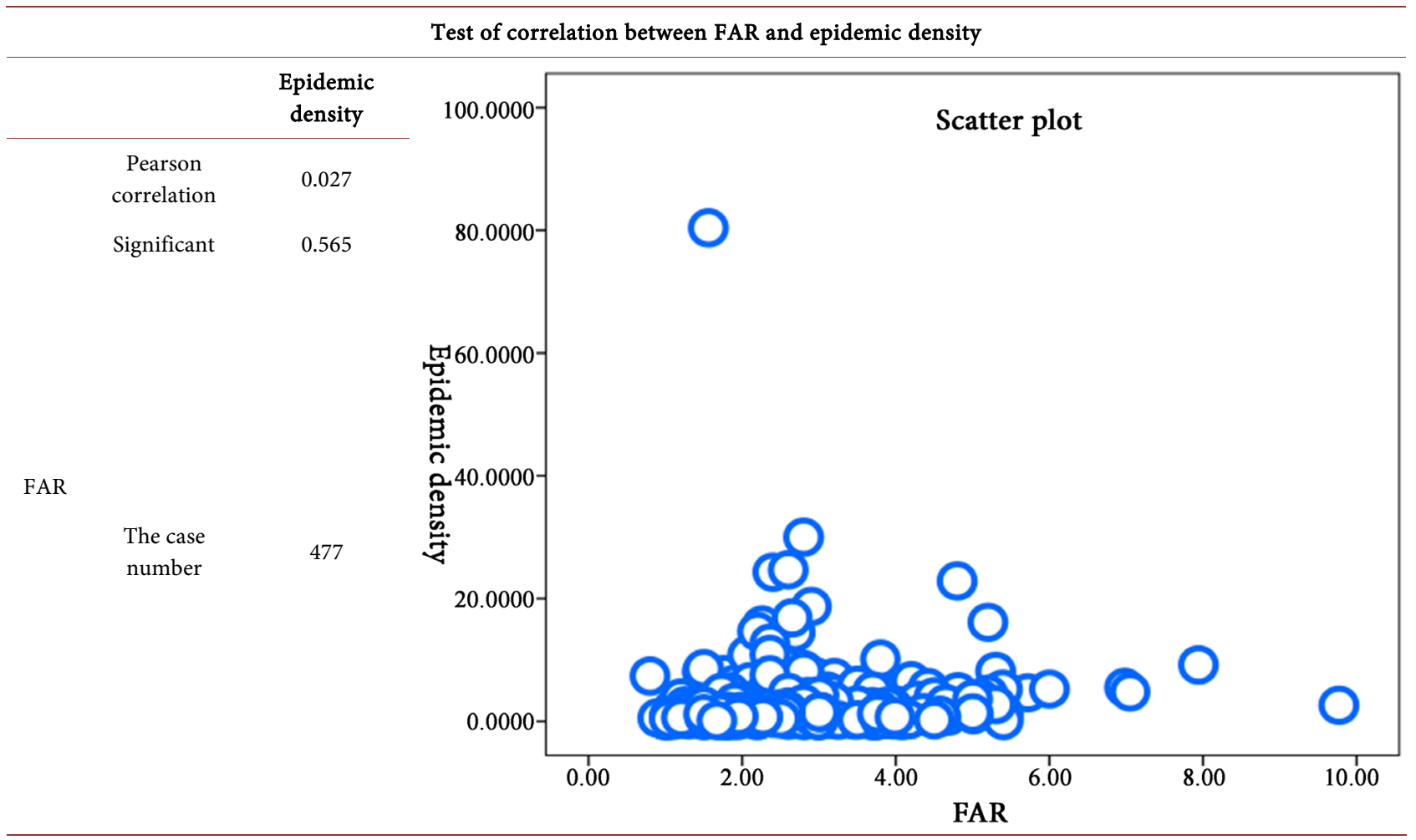

FAR and epidemic density did not reach the relevant significant level of correlation, and the scatter plot of the two showed a weak linear relationship. Therefore, it can be concluded that there is no significant correlation between the FAR of the main urban area of Wuhan and the epidemic density, that is, a high FAR does not necessarily lead to an increase in the number of patients.

Although the urban or residential density is an important planning parameter of the built environment, its impact on SARS-CoV-2 virus infection is unknown. For urban planners, in the context of global urban development, we hope to explore the internal mechanism and connection of virus transmission without changing the characteristics of a high-density urban residential space.

\subsection{Analysis of the Relationship between Residential Density and the Epidemic}

Since the relationship between floor area ratio and the epidemic situation has been analyzed above, we believe that it no longer needs the correlation analysis mentioned above, so it was removed from the physical environment index factors of the plot, and then the next step of principal component analysis was carried out.

In this study, the correlation test was conducted for the remaining 13 factors, and the correlations between the 13 factors and the epidemic density were preliminarily analyzed. As shown in Table 3, the epidemic density is signifycantly related to the base area, land area, building density, building height, building 
Table 3. Pearson's correlation matrix.

\begin{tabular}{|c|c|c|c|c|c|c|c|c|c|c|c|c|c|c|}
\hline & 至 & 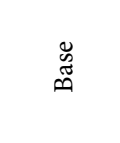 & 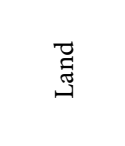 & 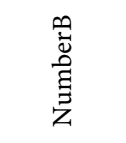 & 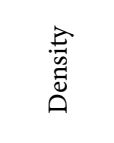 & 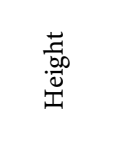 & 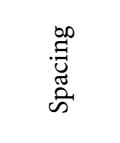 & $\begin{array}{l}\stackrel{\infty}{\Xi} \\
\stackrel{\Xi}{ \pm} \\
\stackrel{0}{J}\end{array}$ & 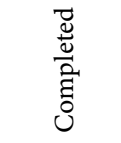 & 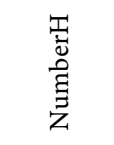 & 定 & 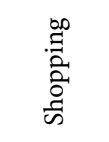 & 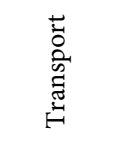 & 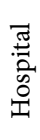 \\
\hline ED & 1 & & & & & & & & & & & & & \\
\hline Base & $-0.147^{\star \star}$ & 1 & & & & & & & & & & & & \\
\hline Land & $-0.199 * *$ & $0.676^{\star *}$ & 1 & & & & & & & & & & & \\
\hline NumberB & $-0.108^{*}$ & $0.857^{\star *}$ & $0.609^{* *}$ & 1 & & & & & & & & & & \\
\hline Density & $0.317^{\star *}$ & $0.138^{* \star}$ & $-0.195^{\star \star}$ & $0.099^{*}$ & 1 & & & & & & & & & \\
\hline Height & $-0.169^{* *}$ & $-0.258^{\star \star}$ & -0.017 & $-0.380^{\star *}$ & $-0.527^{\star *}$ & 1 & & & & & & & & \\
\hline Spacing & $-0.209^{* *}$ & $-0.166^{\star *}$ & 0.016 & $-0.307^{\star *}$ & $-0.510^{\star *}$ & $0.817^{\star *}$ & 1 & & & & & & & \\
\hline Greening & $-0.108^{\star}$ & 0.049 & $0.124^{* *}$ & 0.03 & $-0.221^{\star *}$ & -0.034 & 0.013 & 1 & & & & & & \\
\hline Completed & $-0.242^{\star *}$ & $-0.142^{\star \star}$ & 0.036 & $-0.275^{\star \star}$ & $-0.515^{\star *}$ & $0.694^{\star \star}$ & $0.667^{\star *}$ & 0.076 & 1 & & & & & \\
\hline NumberH & $-0.144^{\star *}$ & $0.583^{\star *}$ & $0.489^{\star *}$ & $0.455^{\star *}$ & $-0.160^{\star *}$ & $0.281^{* *}$ & $0.305^{\star *}$ & -0.014 & $0.207^{\star *}$ & 1 & & & & \\
\hline PD & $0.222^{\star *}$ & $-0.210^{\star *}$ & $-0.273^{\star *}$ & $-0.208^{\star *}$ & $0.211^{* *}$ & -0.047 & -0.085 & $-0.189^{\star *}$ & $-0.171^{\star *}$ & $-0.195^{\star \star}$ & 1 & & & \\
\hline Shopping & $0.111^{*}$ & $-0.117^{\star}$ & $-0.141^{\star *}$ & -0.041 & $0.211^{* *}$ & $-0.098^{\star}$ & $-0.163^{* *}$ & $-0.172^{\star *}$ & $-0.284^{* *}$ & $-0.128^{\star *}$ & $0.528^{\star *}$ & 1 & & \\
\hline Transport & $0.151^{\star *}$ & $-0.179^{\star *}$ & $-0.243^{\star *}$ & $-0.183^{* *}$ & $0.198^{\star *}$ & -0.007 & -0.072 & $-0.174^{\star *}$ & $-0.178^{\star \star}$ & $-0.161^{*}$ & $0.819^{* *}$ & $0.570^{* *}$ & 1 & \\
\hline Hospital & $0.123^{* *}$ & $-0.106^{*}$ & $-0.184^{\star \star}$ & -0.055 & $0.235^{* *}$ & $-0.123^{\star *}$ & $-0.168^{\star *}$ & $-0.210^{\star *}$ & $-0.277^{\star *}$ & $-0.121^{\star}$ & $0.623^{* *}$ & $0.837^{* *}$ & $0.670^{* *}$ & 1 \\
\hline
\end{tabular}

${ }^{* *}$ At the level of 0.01 (double-tailed), the correlation was significant. ${ }^{*}$ At the level of 0.05 (double-tailed), the correlation was significant. ED = Epidemic density; NumberB = number of buildings; NumberH = number of households; $\mathrm{PD}=$ population density.

spacing, completion time, population density, public transportation station density and hospital density, and is related to the number of buildings, greening rate and commercial density. The KMO value of the factor correlation test is 0.767 , indicating that there is an appropriate correlation between the variables. The approximate chi-square value of the Bartlett spherical test is 4310.685 ( $\mathrm{p}<0.001$ ), indicating that the variables are suitable for principal component analysis. Among them, land area, base area, number of buildings, building density, FAR, building spacing, and number of households are highly correlated, and street population density, public transportation station density, commercial density, and hospital density are highly correlated.

After the rotation of the maximum variance of the principal component analysis, four principal components were extracted (Table 4). According to the general experience of urban research, the cumulative contribution rate of the fourth principal component has reached $78.295 \%$, which integrates the information of the original data and can be used to interpret relevant components on behalf of factors.

As can be seen from Table 4, the variance contribution rate of the first principal component is $29.855 \%$, in which the building height is the largest contributor, followed by the building spacing, completion time, and building density, 
Table 4. Principal component rotation component matrix.

\begin{tabular}{ccccc}
\hline Covariance item & Component 1 & Component 2 & Component 3 & Component 4 \\
\hline Base & -0.199 & -0.104 & 0.915 & -0.023 \\
Land & 0.068 & -0.139 & 0.813 & 0.179 \\
NumberB & -0.333 & -0.082 & 0.858 & 0.028 \\
Density & -0.677 & 0.148 & -0.045 & -0.402 \\
Height & 0.925 & 0.003 & -0.085 & -0.081 \\
Spacing & 0.901 & -0.054 & -0.023 & -0.056 \\
Greening & 0.012 & -0.140 & 0.027 & 0.927 \\
Completed & 0.818 & -0.203 & -0.056 & 0.032 \\
NumberH & 0.370 & -0.061 & 0.754 & -0.159 \\
PD & -0.047 & 0.827 & -0.189 & -0.089 \\
Shopping & -0.136 & 0.841 & -0.017 & -0.028 \\
Transport & -0.023 & 0.867 & -0.142 & -0.068 \\
Hospital & -0.138 & 0.893 & -0.027 & -0.074 \\
The eigenvalue & 3.881 & 3.238 & 2.040 & 1.019 \\
Variance & 29.855 & 24.910 & 15.695 & 7.835 \\
contribution rate & & & & 70.295 \\
Cumulative & 29.855 & 54.764 & 70.460 & \\
contribution rate & & & &
\end{tabular}

which mainly reflects the quality of "Building construction" of the community. It can also be said to be the intuitive image of the community. The variance contribution rate of the second principal component is $24.910 \%$, which combines the information of hospital density, public transport station density, commercial density and population density, and mainly reflects the convenience index of urban traffic activities and supporting facilities in the outer space of the community, which can be called the quality of "Life service". The variance contribution rate of the third principal component is $15.695 \%$, which reflects the quality of "Community scale" by combining the information of base area, land area, number of buildings and number of households. The variance contribution rate of the fourth principal component is $7.835 \%$, which mainly reflects the quality of the "Living environment" of the community.

Principal component analysis (PCA) has been applied to the comprehensive evaluation of urban planning statistical variables by eliminating overlapping information through dimensionality reduction. The four principal component factors of the principal component analysis in this study provide a clearer and more comprehensive overview of the influencing factors of the epidemic distribution at the community level.

\subsection{Multiple Linear Regression Analysis}

The four factors after principal component analysis were set as $X_{1}$ (building con- 
struction), $X_{2}$ (Life Services), $X_{3}$ (Community scale), and $X_{4}$ (Living environment) and $Y$ (epidemic density) for multiple linear regression analysis. The results showed that the DW value is 2.031 ( $\mathrm{p}<0.001$ ), which is statistically significant, indicating that the regression model had good explanatory power. The regression results showed that all the indicators are significantly correlated with the epidemic density (significance value $<0.01$ ). The final regression equation obtained from Table 5 is as follow.

$$
Y=2.919-1.201 X_{1}+0.625 X_{2}-0.888 X_{3}-0.699 X_{4}
$$

According to the distribution of the results of multiple linear regression analysis of principal components (Figure 9), the epidemic density is highly negatively correlated with the quality of building construction, highly positively correlated with life services, highly negatively correlated with the scale of the community, and highly negatively correlated with the living environment (mainly the ratio of green space). This is consistent with correlation analysis and principal component analysis.

\subsection{Summary}

Through a series of analysis, it can be found that: for the planning and design indicators of the community, the larger the land scale (including land area, base area, number of buildings and household number), the smaller the epidemic density. The author speculates that the reasons may be as follows: first, the area of the residential area is large, and the traffic relationship with the outside world is weakened in the unit area, and the frequency of personnel flow is decreased; Second, due to the development of modern infrastructure, most of the communities with the large land area are newly built communities. These communities are better than the old ones in terms of supporting facilities and spatial planning, and they have a stronger defense against transmitted diseases and a lower chance of being infected.

In general, building density and building height tend to be negatively correlated

Table 5. Main component factor multi-line regression result.

\begin{tabular}{|c|c|c|c|c|c|}
\hline & \multicolumn{2}{|c|}{$\begin{array}{l}\text { Unnormalized } \\
\text { coefficient }\end{array}$} & \multirow{2}{*}{$\begin{array}{c}\text { Normalized } \\
\text { coefficient } \\
\text { Beta }\end{array}$} & \multirow{2}{*}{$\mathbf{t}$} & \multirow{2}{*}{ Significant } \\
\hline & B & $\begin{array}{l}\text { Standard } \\
\text { error }\end{array}$ & & & \\
\hline (constant) & 2.919 & 0.222 & & 13.144 & 0.000 \\
\hline $\begin{array}{c}X_{I} \text { (Building } \\
\text { construction) }\end{array}$ & -1.201 & 0.222 & -0.240 & -5.403 & 0.000 \\
\hline$X_{2}$ (Life services) & 0.625 & 0.222 & 0.125 & 2.810 & 0.005 \\
\hline$X_{3}$ (Community scale) & -0.888 & 0.222 & -0.178 & -3.996 & 0.000 \\
\hline$X_{4}$ (Living environment) & -0.699 & 0.222 & -0.140 & -3.144 & 0.002 \\
\hline
\end{tabular}




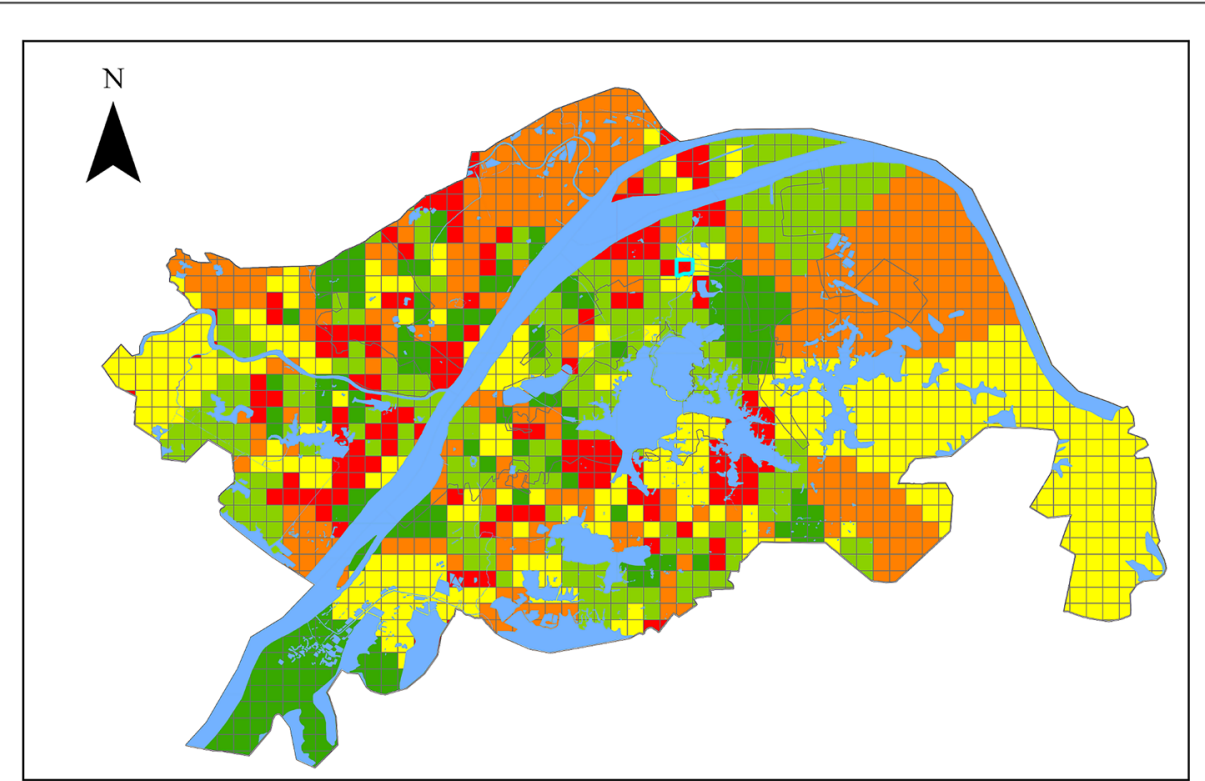

Figure legend

Building construction

poor

\begin{tabular}{|l|}
\hline \\
\hline \\
\hline \\
\hline \\
\end{tabular}

(a)

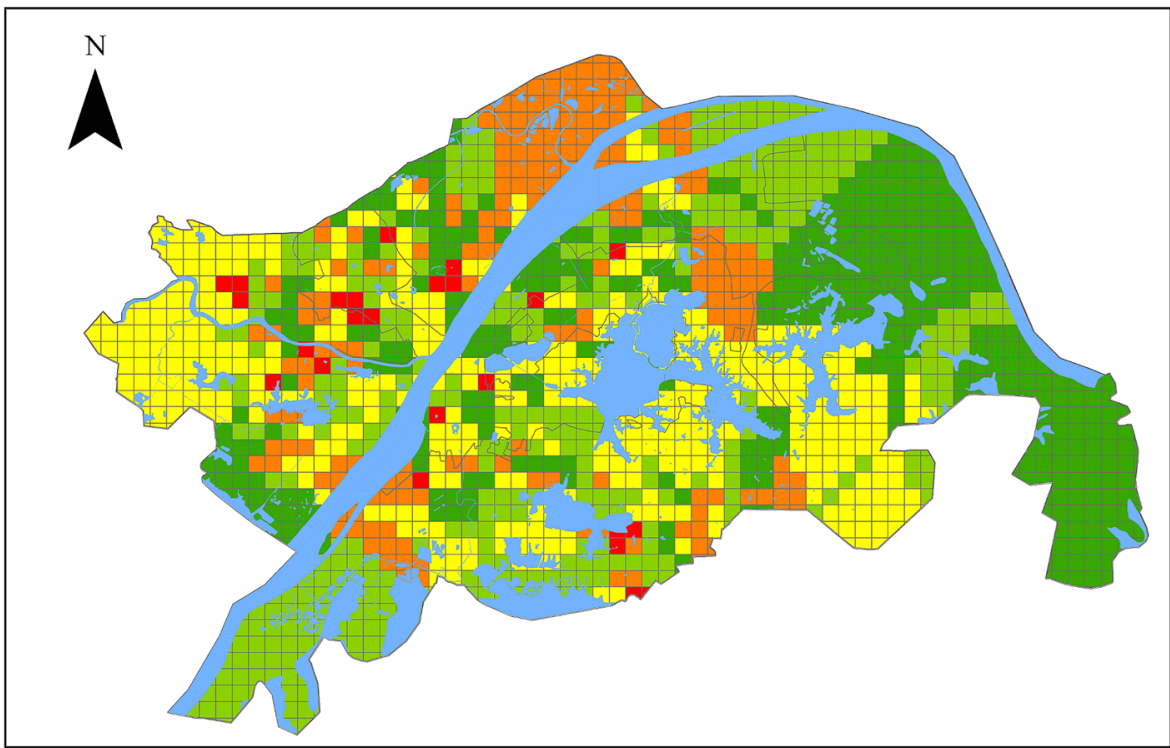

Figure legend

Living Environment

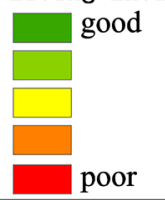

(b) 


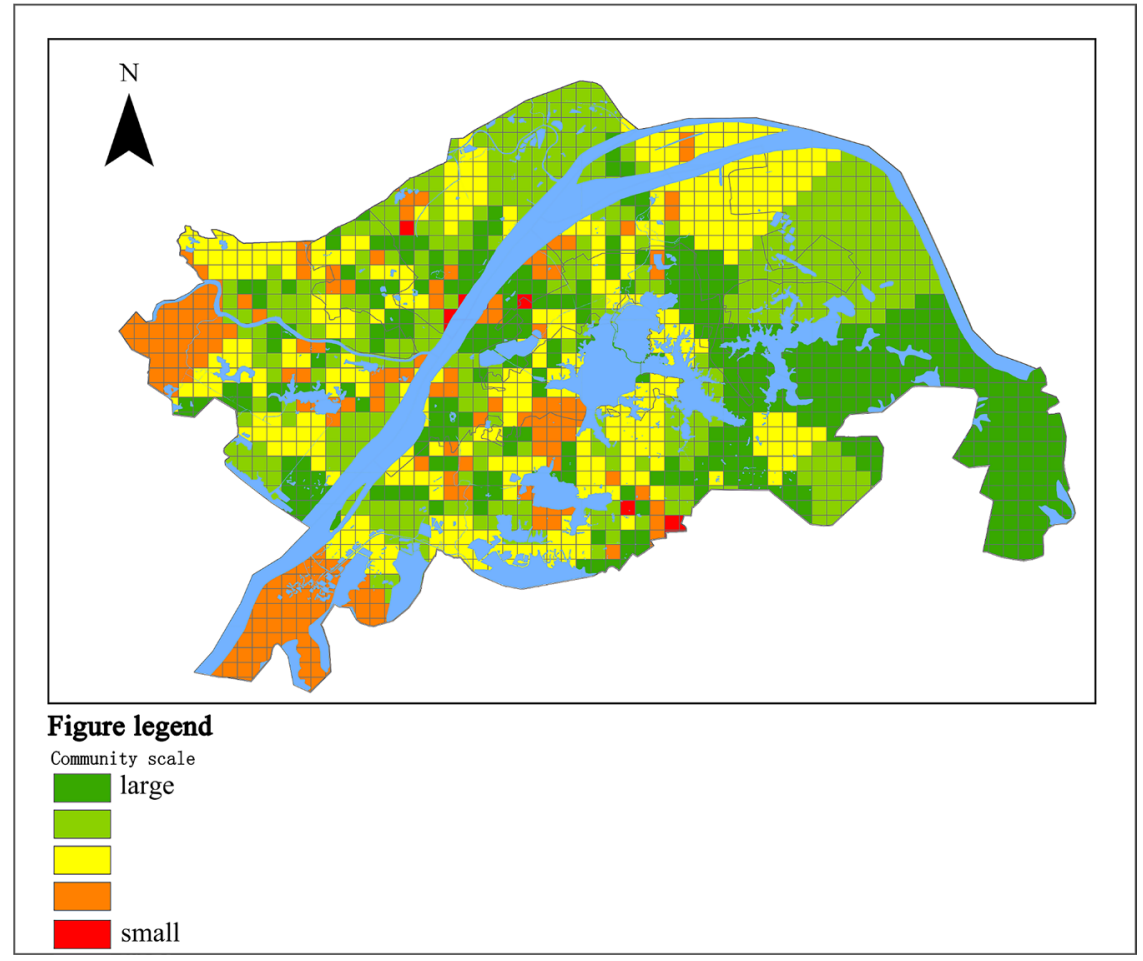

(c)

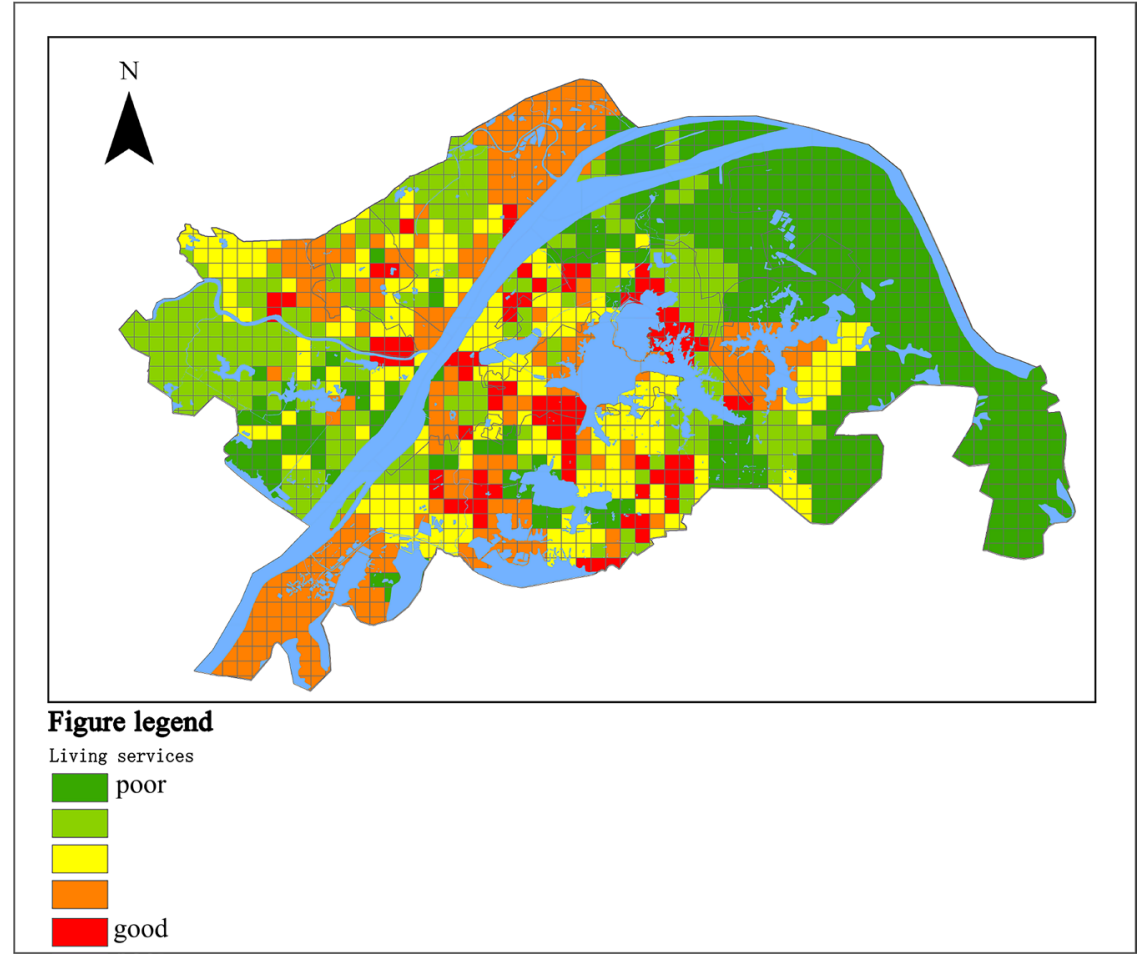

(d)

Figure 9. Distribution of multivariate linear regression results. (a) First Principal Component (Building Construction); (b) Second Principal Component (Life Services); (c) Third principal component (community scale) (d) Fourth principal component (living environment). 
in the case of similar residential density. The results show that when the building height is larger, the epidemic density is lower, which in turn also indicates that the building density in the com-munity with high epidemic density is larger.

In addition, the coefficient of building height in the first principal component of principal component analysis reached 0.925 and showed a negative correlation with height. The possible reasons for the inhibition of the epidemic in highrise residential buildings are that COVID-19 can be transmitted through aerosols. And the ground air in high-rise buildings is more difficult to spread outward, while the virus stays in the lower space of buildings for a longer time. However, the air density in high buildings is lower, and the possibility of exposure to the potential virus is reduced.

The epidemic density and the greening rate are also negatively correlated. Exposure to green space can increase lighting and ventilation, block the spread of epidemic diseases, and eliminate some negative emotions (Zhang et al., 2021). During the SARS epidemic, among the three cities of Guangzhou, Shenzhen and Hong Kong, which are basically the same size, the death toll in Guangzhou and Hong Kong far exceeded that of Shenzhen. According to scholars, residential areas in Shenzhen have the advantages of agglomeration distribution, large spacing, and good ventilation and sunshine conditions. Therefore, communities with a high greening rate should have more advantages in epidemic prevention and control.

The older the construction of the community, the smaller the height, building spacing, etc., and the larger the building density, and the overall facilities of the community are relatively old and imperfect. Such fragile communities are more likely to become places where the virus spreads.

Modern residential management mode uses all kinds of boundaries to separate residential areas in the form of units, but urban spaces are closely connected and mutually influenced. The COVID-19 belongs to the type of infectious disease transmitted through air. The air mobility in the main urban area with high development intensity is relatively poor. The convenience index of living services and other facilities around the community also has a certain impact on the spread of the epidemic. Communities with good traffic conditions, wide commercial distribution, and high accessibility of hospitals and medical services have high population density and more frequent movement of people, and residents in communities are more likely to be exposed to a potential virus environment. It is consistent with the results of urban spatial factor analysis above. In addition, it is worth noting that, in the case that the scale and construction environment of some communities seem not easy to develop into the hardest-hit areas, the urban spatial environment outside the communities may be an important factor that dominates its development into a highly diseased community. For example, in Jianghan District and Wuchang District, a considerable part of the residential and commercial mixed communities along the river are also small in scale, with good construction quality, but its high traffic index and high density of public 
open spaces such as businesses and hospitals lead to a relatively high number of infected cases in these areas.

\section{Discussion and Conclusion}

\subsection{Discuss}

\subsubsection{The Degree of Influence of Community Construction Planning Factors on the Occurrence of the Epidemic}

This study explores the internal relationship between the factors of community construction planning and the occurrence of COVID-19 by analyzing the degree of influence of relevant construction indicators inside and near the urban community on the outbreak density. The factor that has a greater impact on the distribution of the epidemic is the building construction of the community. The epidemic in Wuhan mostly occurred in relatively old com-munities in the main urban area. The overall construction plan inside the community is relatively backward. The existing epidemic prevention system in these communities can hardly play a role in quickly stopping the spread of the disease before and after an outbreak. As for the construction planning factors near the community, the more perfect the current nearby traffic, the higher the proportion of commercial land. And the higher the level of commercial supporting facilities and the more complete the community which virus spreads faster. For example, Jiang'an District became the hardest-hit area of the epidemic because of commercial factors. As the Spring Festival approached, community residents began to move around frequently and purchased Chinese New Year goods. Besides, modern commerce and traditional neighborhoods coexist in the Hankou area. The population base of the elderly retired group is relatively large. Therefore, their exposure to viral environments also increases.

\subsubsection{The Construction of a Diversified and Flexible Epidemic Prevention Space in the Future Community}

The function of the current urban community is relatively single, especially not having the flexibility to respond to impulsive emergencies. Survivability is the basic ability of urban development (Wu et al., 2020a). In the post-epidemic era, urban planning should reflect and learn promptly, and actively build a diversified and sustainable development of healthy communities.

In residential areas, the open layout of multiple centers is helpful for lighting and ventilation, and reduces the probability of virus cross-infection at the same time. The diversified residential space pattern with multiple centers, multiple clusters and green areas can create flexible residential spaces. And enhance the resilience and elasticity of the planning environment of the community construction. Corresponding anti-epidemic settings can also be setup in some public spaces of residential buildings, such as elevators, open platforms, and corridors.

As for the urban space environment near the community, the community along the traffic track is more susceptible to spreading diseases. Consider setting up flexible buffer spaces between the community and the line, such as linear parks, 
street corner green spaces and open spaces, to enrich the community's natural landscape system in the meanwhile. Special attention should be paid to the prevention and control planning of large commercial areas to avoid such commercial open spaces becoming a potential source of virus transmission in nearby communities. In the residential quarters around the general hospital, it is important to create a suitable living environment for the residents of these communities, and planning should be done strictly for traffic route control, spatial isolation and regular ventilation.

Reflecting on the challenges posed to cities by the epidemic, it is imperative to build a healthy, safe, and sustainable living environment (2016). Therefore, in the post-epidemic and re-epidemic period when epidemic prevention is normalized, flexibility, resilience and the construction of a resilient spatial system in communities will be important in urban residential planning and epidemic prevention and control.

\subsubsection{Public Health Prevention and Control in the Smart City of the Future}

Analysis modes such as geographic information system, Internet of Things, mobile phone signaling and POI data based on smart big data have been favored by urban planning scholars in recent years (Meijer \& Bolivar, 2016). From the perspective of urban planning, we should pay attention to the construction of basic data platforms. The big data is fully applied to the surveillance discovery and tracking of the epidemic, the exploration of the spatial distribution characteristics of the epidemic and its factors, the prediction and simulation of the spatial and temporal evolution of the epidemic, and the analysis of the impact mechanism of public intervention policies. For example, Zhu Yimin et al. established a COVID-19 control model based on isolation measures based on the actual situation of confirmed and suspected patients being isolated and observed. They eventually developed a control model for COVID-19 outbreak based on isolation measures, which made some predictions for the outbreak development (Zhu et al., 2020).

Big data also plays a role in spatial resource allocation and refined community management (Wu et al., 2020b). In the event of a major public health event, how can smart transportation and smart infrastructure be used to help materials reach their destination as efficiently as possible (Magare et al., 2020)? How to ensure that the city's power grid is unobstructed temporarily to obtain rescue information? How to use the digital panoramic immersion experience to satisfy people's de-sire for outdoor space during the epidemic...... In a word, it is a major challenge for urban planning to build an intelligent "digital strategy" mode to help urban public health governance and guide urban development and growth.

\subsection{Conclusion}

We analyzed the characteristic distribution and related influencing factors of the COVID-19 epidemic community in Wuhan from a spatial perspective. The dis- 
tribution of epidemic communities in the main urban area of Wuhan presents significant spatial auto-correlation, forming a spatial pattern of "One Belt and Three Core", which is concentrated in the main urban area along the Changjiang River, including Jianghan District, Wuchang District, Hanyang District, and Jiangan District. The high-high clusters and hot spot areas are mainly concentrated in the central and northern part of the main urban area, such as Jianghan District, the southern part of Jiangan District and the northern part of Wuchang District. While the low-low clusters and cold spot areas are mostly distributed in the northern part of Jiangan District, the southern part of Qingshan District and the southern part of Hongshan District.

This study analyzes the influence mechanism of community construction planning factors on the epidemic as follows:

1) In terms of community scale, building construction, and living environment, there is no significant correlation between FAR and epidemic density when the built environment (land-use intensity) is similar. The epidemic density is negatively correlated with the land area, base area, number of households, building height, building spacing, and completion time, negatively correlated with the number of buildings and greening rate, and positively correlated with the building density of the community. Overall, the better residents' living conditions, the less risk of transmission and infection.

2) In terms of living services near the community, it can be considered that the distribution of traffic stations, commercial facilities and medical institutions within the 15-minute living circle of the residential area has an impact on the occurrence of the epidemic in those communities. The density of these living service facilities and the epidemic density often present the phenomenon of "antinomy". It means that communities with high traffic accessibility and high density of commercial facilities often suffer more from public health emergencies.

The epidemic is still spreading all over the world. The correlation between the index factors and the epidemic density obtained in this study can provide technicality quantitative support and reference for the residential space planning and governance in Wuhan and other similar cities or regions. It also provides suggestions for the improvement of the prevention and control system of urban public health events in the post-epidemic and re-epidemic periods.

\subsection{Limitations of This Study}

We acknowledge that there are certain limitations of this study. First, the data on cases in epidemic plots are somewhat time-sensitive, and there is a tentative lack of official data, which can cause some bias to the study results. Second, the construction planning indicator factors we have studied so far do not provide a comprehensive overview of the mechanisms of the spread of the epidemic such as the distribution of the epidemic among different population ages in the plots needs to be further supplemented. Third, the perspective of this paper is only the physical spatial environment; the generation of epidemic is also related to economic, 
social, cultural and behavioral factors, which should also be taken into account, and the interaction between physical and social environments should be focused on in future studies.

\section{Supplementary Materials}

The above pictures are drawn by the authors.

\section{Acknowledgements}

Acknowledgments: The authors would like to thank all reviewers for their valuable comments on this thesis, which allowed us to find many details worthy of improvement and made our paper more clear and complete.

\section{Conflicts of Interest}

The authors declare no conflicts of interest regarding the publication of this paper.

\section{References}

Anselin, L., \& Getis, A. (2010). Spatial Statistical Analysis and Geographic Information Systems. In Advances in Spatial Science (pp. 35-47). Springer International Publishing.

Cao, H., \& Liang, S. (2020). The "Precise Control" of Community Public Health Emergency Management-Realistic Dilemma, Logical Approach and Governance Strategy. Theoretical Discussion, No. 3, 149-157.

Cao, Z. D., Wang, J. F., Gao, G., Han, W. G., Feng, X. L., \& Zeng, G. (2008). Spatial Pattern and Heterogeneity Risk of Severe Acute Respiratory Syndrome Epidemic in Guangzhou. Geographic Research, No. 5, 1139-1149+1226.

Chen, L. P., Yu, F. Q. H., Sun, S. H., Liu, X. Y., Sun Z. K., Cao, W. X. et al. (2021). Evaluation Indicators of Ruditapes philippinarum Nutritional Quality. Journal of Food Science and Technology, No. 8, 2943-2951.

Chen, X., Huang, Y. J., Li, J. H., Wang, S. Y., Pei, T. et al. (2020). Clustering Characteristics of COVID-19 Cases and Influencing Factors in Chongqing Municipality. Progress in Geography, No. 11, 1798-1808.

Dong, X. (2005). Preliminary Study on the Transmission and Control of Diseases in Buildings and Residential Districts. Tsinghua University.

https://kns.cnki.net/KCMS/detail/detail.aspx?dbname $=$ CMFD0506\&filename $=2006066$ $\underline{754 . n h}$

Eisen, L., \& Eisen, R. J. (2011). Using Geographic Information Systems and Decision Support Systems for the Prediction, Prevention, and Control of Vector-Borne Diseases. Annual Review of Entomology, 56, 41-61.

Hao, X., \& Yan, H. (2020). Simulating the Infected Population and Spread Trend of COVID-19 under Different Policy by EIR Model. SSRN Electronic Journal.

Jin, A. N., Li, G., Wang, J. B., Xu, T. T., Yu, Y., Hu, Z. H., \& Yang, J. C. (2020). SpatioTemporal Evolution and Control Strategies of COVID-19 Epidemic in Shenzhen, China. Journal of Shaanxi Normal University Natural Science Edition, No. 3, 18-32.

Jin, L. (2003). Research on the Strategy of Urban Comprehensive Disaster Reduction Crisis Planning. China Investigation and Design, No. 10, 20-24. 
Li, B., \& Zhang, L. (2003). The Inspiration of Outbreak of SARS to the Urban Planning in China. City Planning Review, No. 7, 71-72.

Li, G., Wang, J. B., Xu, T. T., Xi, X., J, A. N., \& Yu, Y. (2020a). Spatio-Temporal Evolution Process and Integrated Measures for Prevention and Control of COVID-19 Epidemic in China. Acta Geographica Sinica, No. 11, 2475-2489.

Li, Q. Q., Gao, M., Zheng, T. F., \& Hu, W. (2020b). Spatial Epidemiological Analysis of COVID-19 in Guangdong Province. Journal of Chongqing Medical University, 7, 904910.

Li, X., Zhou, L., Jia, T., Wu, H., Zou, Y. L., \& Qin, K. (2020c). Influence of Urban Factors on the COVID-19 Epidemic: A Case Study of Wuhan City. Geomatics and Information Science of Wuhan University, No. 6, 826-835.

Li, Y., \& Hou, J. (2020). 3 Combinations of Public Health and Architecture. Architectural Creation, No. 4, 30-37.

Ma, Y. W., Pan, C. L., \& Meng, C. (2020). Research on the Relationship between the Characteristics of Residential Space and the Spatial Distribution of COVID-19 in Wuhan City. Geo-Spatial Information, No. 11, 43-47+6.

Magare, S. S., Kondekar, S. R., \& Dudhgaonkar, A. A. (2020). Smart City during COVID19 Lockdown and Its Future Impact. 2020 International Conference on Smart Innovations in Design, Environment, Management, Planning and Computing (ICSIDEMPC), Aurangabad, 30-31 October 2020, 209-215. https://doi.org/10.1109/ICSIDEMPC49020.2020.9299589

Meijer, A., \& Bolivar, M. P. R. (2016). Governing the Smart City: A Review of the Literature on Smart Urban Governance. International Review of Administrative Sciences, 82, $1-17$.

Niu, Q., Wu, W., Shen, J., Huang, J., \& Zhou, Q. (2021). Relationship between Built Environment and COVID-19 Dispersal Based on Age Stratification: A Case Study of Wuhan. International Journal of Environmental Research and Public Health, 18, 7563.

Tao, Z. (2020). Discussion on Several Basic Issues of Intensive Utilization of Urban Land. China Land Science, 14, 1-5.

Tobler, W. R. (1970). A Computer Movie Simulating Urban Growth in the Detroit Region. Economic Geography, 46, 234-240. https://doi.org/10.2307/143141

Wang, J., Wu, X., Wang, R., He, D., Li, D., Yang, L. et al. (2021). Review of Associations between Built Environment Characteristics and Severe Acute Respiratory Syndrome Coronavirus 2 Infection Risk. International Journal of Environmental Research and Public Health, 18, 7561. https://doi.org/10.3390/ijerph18147561

Wu, Z. Q., Lu, F. D., Yang, T., Feng, F., \& He, R. (2020a). Challenges for Urban Space Governance under the Major Epidemic Impact. Urban Planning Review, No. 8.

Wu, Z. Q., Wang, K., Chen, W., Yang, Y. D., Ren, G. Y., Chen, Q. R. et al. (2020b). Symposium on Innovations in Fine-Tuned Spatial Governance. Urban Planning Forum, No. 3, $1-14$.

Xue, G. (2020). From SARS to COVID-19, Community Prevention and Control Still Need to Be Improved. China Health, No. 5, 71-72.

Yang, R., Ou, Y., \& Tian, L. (2018). Origin, Development and Evolution of Urban Planning and Public Health. Shanghai Urban Planning, No. 3, 79-85.

Ye, Z. (2020). Simulation of Epidemic Spread in Urban Space-The Case Study of Wuhan Central City During the Epidemic Period of COVID-19. South Architecture, 1-10.

Zhang, L. N., Chen, R. J., Meng, X., \& Kan, H. D. (2021). Research Progress on Exposure 
and Health Effects of Green Space. Journal of Environmental and Occupational Medicine, No. 2, 175-182.

Zhang, Y., \& Lu, J. (2003). Community Construction Is Important Because of SARS. Information for Decisions Magazine, No. 20, 17.

Zhang, Y., Li, Y., Yang, B., Zheng, X., \& Chen, M. (2020). Risk Assessment of Covid-19 Based on Multisource Data from a Geographical View. IEEE Access, 8, 125702-125713. https://doi.org/10.1109/ACCESS.2020.3004933

Zheng, T., \& Liu, H. (2020). Exploration of the Built-Environmental Elements that Influence the Spread of COVID-19 Epidemic on Community Scale: A Case Study of Wuhan, China. Modern Urban Research, No. 10, 20-29.

Zhou, T., Liu, Q. H., Yang, Z. M., Liao, J. Y., Yang, K. X., B, W. et al. (2020). The Basic Reproduction Number of COVID-19. Chinese Journal of Evidence-Based Medicine, No. 3, 359-364.

Zhou, W. (2020). Research on the Correlation between Urban Built Environment and High-Risk Communities under Epidemic Situation Based on the Sample of Seven Urban Communities in Hankou. New Architecture, No. 6, 52-55.

Zhu, Y., Liu, D. Q., Mei, L. Y., Li, L., Huang, L. H., Lei, Y. et al. (2021). Evolution of the Spatial Distribution Pattern of COVID-19 in Chongqing, China, Based on Geographic Information. Chinese Journal of Virology, No. 2, 292-299.

Zhu, Y. M., Huang, B., Wang, Z. Z., Ju, J. J., \& Zhu, L. Q. (2020). Analysis of the Isolation Measure on the Control Model of COVID-19. Journal of Wuhan University (Science Edition), No. 5, 442-450. 